Sharif University of Technology
Scientia Iranica
Transactions B: Mechanical Engineering
hCIENTIA

\title{
Multi-layer advanced fiber hybridisation (glass-carbon-Kevlar) and variable stiffness effect on composite structure responses (stress and deformation): An FE approach
}

\author{
P. Sahu ${ }^{a}$, N. Sharma ${ }^{a, *}$, and S.K. Panda ${ }^{b}$ \\ a. School of Mechanical Engineering, KIIT, (Deemed to be University) Bhubaneswar, 751024, India. \\ b. Department of Mechanical Engineering, NIT Rourkela, 769008, India.
}

Received 23 September 2020; received in revised form 31 October 2020; accepted 7 December 2020

\section{KEYWORDS}

Flexural behaviour;

Hybrid composite

laminates;

HSDT;

Geometrical

parameters;

FEM;

MATLAB

\begin{abstract}
In the present study the effect of the single and multilayer advanced fiber hybridization on the composite structural stiffness (deformation resistance capability) and the stress behavior under the variable loading (uniformly distributed and sinusoidal) was analyzed numerically using an isoparametric finite element approach. The hybrid composite panel model was derived in the framework of the higher-order kinematic model to satisfy the inter-laminar stress continuity via the strains. The necessary structural equilibrium equations under the influence of variable mechanical loadings are derived through the variational principle to compute the panel central point deflections, as well as the stress values. The varied structural stiffness and their corresponding deflection parameters due to the hybridization of different advanced fibers (carbon/glass/kevlar) are obtained using an in-house MATLAB code by incorporating the necessary elastic constant through the constitutive relationship. Firstly, the previous field studies served as a background and some similar examples are solved to ensure the correctness of the solution, the steadiness of the numerical solution is confirmed and extended further. Finally, the effect of the variable structural parameters relevant to the geometry (thickness ratio, aspect ratio), boundary conditions, and the order of hybridizing layers (glass-carbon-kevlar) on the bending strength is highlighted and explained by solving a series of examples.

(C) 2021 Sharif University of Technology. All rights reserved.
\end{abstract}

\section{Introduction}

The traditional materials have been successfully replaced by hybrid composite materials for many lightweight and high strength applications. In a

\footnotetext{
*. Corresponding author. Tel.: +91-9658780735 E-mail addresses: psahumech@gmail.com (P. Sahu); nitin.sharmafme@kiit.ac.in (N.Sharma); pandask@nitrkl.ac.in (S.K.Panda)
}

new type of advanced material configuration, a single polymer matrix contains two or more reinforced fibers. This led to the high diversity of the material properties and the material having this characteristic are called the hybrid composites. Thus, the investigation of the mechanical properties like hardness, tensile strength, compression strength, impact strength, and flexural strength of this advanced hybrid material is necessary. Among these properties, the flexural strength is determined through a three-point bend test, in which the specimen having some span length deflects under the load until a fracture occurs. Due to the anisotropic 
material property of the specimen, the bending failure would occur as the result of the tensile, compressive, shear, or a combination of all these stresses. The hybrid composites are more efficient compared to the traditional ones and some advantages such as being cost-effective caused them to be preferred over their traditional counterparts. Some researchers have investigated the flexural properties of various types of hybrid materials via experimental, numerical, and analytical methods. The mechanical and thermo-mechanical behaviour such as tensile, compressive, flexural, interlaminar and impact strength of woven fabric glasskevlar/epoxy composites $[1,2]$ under different types of loading such as Uniformly Distributed Load (UDL) and Sinusoidal Distributed Load (SDL) has been studied. The aforementioned properties of the plain kevlar fabric have also been investigated and compared with glass-kevlar hybrid composite [3] to determine whether the hybrid composites show better strength than single fiber-reinforced composite material. The hybridization effect of glass fiber on the sisal fiber polypropylene composites has been studied [4] and it has been observed that the tensile, flexural, and impact strength is enhanced without affecting the tensile and flexural moduli. Also, the results of the study conducted on the flexural behavior of glass-hemp-glass hybrid composite showed that the hybrid composites are more beneficial than the traditional materials in terms of economic efficiency, ecological, recycling value, and specific fatigue strength [5]. Further, the flexural modulus of the carbon/basalt hybrid composite was found to depend upon their compositions according to the rule of mixture $[6,7]$. The investigation on tensile and compressive in-plane mechanical properties under quasi-static loading of different combinations of glass-carbon hybrid composites showed that the tensile strength and ultimate tensile strain increased with the increase of the percentage of glass fiber [8]. The flexural strength and modulus of carbon-basalt hybrid composite are strongly dependent on the different sequences of fiber reinforcement [9]. Moreover, the flexural progressive failure modes of carbon and glass fiber inter-layer and intra-layer hybrid composites have also been investigated [10]. The experimental analysis on the flexural behaviour of two different sandwich hybrid composites-aramid fiber in the skin and carbon or glass in the core; and aramid in core and carbon or glass in skin-has been carried out and the bending stress behaviour has been observed to be higher at the coreskin interface than at the core surface [11]. Dong and his colleagues $[12,13]$ reported the flexural properties by taking different grades of glass and carbon fiber reinforced epoxy hybrid composites and suggested that the flexure modulus decreases with the increase of the percentage of glass fiber [14] and the flexural strength decreases when the carbon/epoxy laminate is replaced by glass/epoxy laminas partially [15]. Naidu et al. [16] reported that the addition of up to $2 \%$ graphitic carbon nitride $\left(\mathrm{g}-\mathrm{C}_{3} \mathrm{~N}_{4}\right)$ filler leads to an increase in bending strength of hybrid glass fiber composite. Doddi et al. [17] investigated the effect of the fiber angle on the dynamic properties of the pineapple leaf fiber hybridized with basalt reinforced epoxy composite. James et al. [18] observed the effect of bagasse/sisal fiber layup scheme on the mechanical properties of hybrid composites.

As far as the numerical prediction of responses is concerned, several displacement kinematic models [1924] have been used for the analysis of the flexural and vibration analysis of composite structures such as laminated composite $[25,26]$ as well as functionally graded structures [27-30], a viscoelastic microcomposite beam [31] and sandwich doubly curved nanocomposite panel [32]. Reddy and Liu [33] employed Higher-order Shear Deformation Theory (HSDT) for determining the through-thickness variation of the transverse shear strains, and the effect of the support conditions, and loading type in the simply supported cylindrical and spherical orthotropic laminated shells. Xiao et al. [34] analyzed the static infinitesimal deformations of thick laminated composite elastic plates using Higher-Order Shear and Normal Deformable Plate Theory (HOSNDPT) via a meshless method under different support conditions. The effect of the delamination on the flexural responses has also been investigated in detail by many researchers $[35,36]$. The commercial Finite Element (FE) tools such as ANSYS have been used by some researchers to study the free vibration responses of the laminated composite intact [37], damaged beams [38] and hybrid laminates [39]. The Finite Element Analysis (FEA) in conjunction with the Classical Lamination Theory (CLT) has also been employed to study the effect of stacking sequence on the flexural properties of glasscarbon fiber [40]. Moreover, an optimal design for the flexural behaviour of glass and carbon fiber reinforced polymer hybrid composites has been reported [41].

Subsequently, several studies on the bending and stress behaviour of carbon nanotube-reinforced hybrid composite plates have been conducted [42-47] The bending and free vibration of thin-to-moderately thick hybrid composite plates reinforced by single-walled carbon nanotubes were analysed [48]. Also, the effect of matrix cracks on the bending and vibration behaviours of hybrid laminated plates made of Carbon Nanotube Reinforced Functionally Graded (CNTR-FG) layers and conventional graphite fiber reinforced composite layers have been investigated by Lei et al. [49].

This concise review of the field literature portrays that numerous studies have been performed to analyze the structural performance of the laminated composite structures both numerically and experimentally. It is 


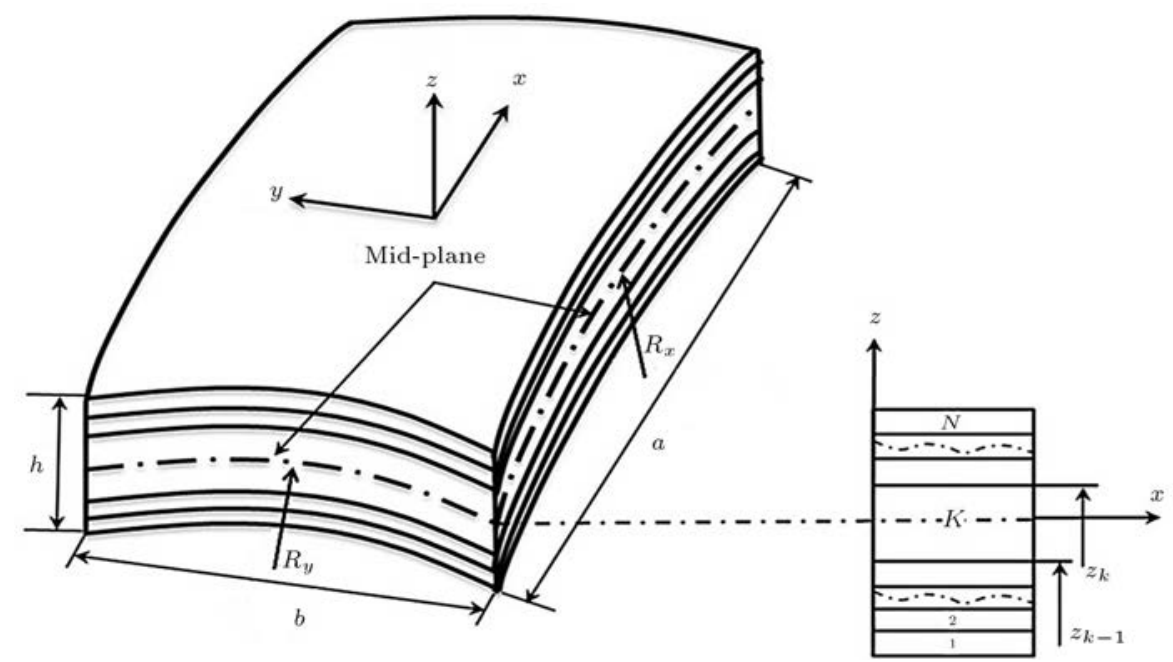

Figure 1. Curved composite shell panel geometry and stacking sequence.

structures both numerically and experimentally. It is safe to infer that the majority of the works have been dedicated to the experimental characterization and evaluation of the effect of the hybridization on the mechanical properties. Also, a variety of methods (analytical/numerical) have been employed for model verification and performance assessment of the newly proposed solution techniques. Only a few studies have addressed the deflections and stresses in the laminated hybrid composite panel due to varying load, structural parameters, support conditions, and hybrid type in the framework of a more accurate higherorder displacement model such as HSDT. Moreover, the flexural responses of curved hybrid composite panels are investigated scarcely. Therefore, to bridge this knowledge gap, the flexural behaviour of hybrid (glass-carbon-kevlar) laminated composite curved shell panels subjected to varying loading conditions has been analyzed. A FE model has been implemented in the framework of HSDT. A nine-noded Lagrangian isoparametric element was used for discretization purpose. The curvature effect was incorporated to have cylindrical, spherical, elliptical, hyperboloid, and flat shell panel geometries. The accuracy of this model was ascertained by reproducing the benchmark results reported in the previous studies using the scheme under discussion. Subsequently, the above mentioned model was extended to solve several parametric examples to understand the flexural and stress characteristics of the laminated hybrid composites curved shell panels through investigating varying material and geometric parameters.

\section{Mathematical formulation}

The geometry of the curved laminated composite shell panel is depicted in Figure 1. The length, width, and thickness of the panel are considered to be ' $a$ ', ' $b$ ', and ' $h$ ', respectively. The panel has curvature in longitudinal and transverse direction the radius of which is denoted by $R_{x}$ and $R_{y}$, respectively. Depending on the relation between $R_{x}$ and $R_{y}$ five geometrical shapes are realized namely, flat, cylindrical, spherical, elliptical, and hyperboloid. Figure 2 portrays the geometrical shapes and the corresponding relations between $R_{x}$ and $R_{y}$.

Now, the displacement model for the deflection $\left(u_{l}, v_{m}\right.$, and $\left.w_{n}\right)$ of any point within the panel in terms of the deflection of any point lying on the midplane is represented as:

$$
\left.\begin{array}{l}
u_{l}=\left[u_{l i}\right]\{\bar{z}\} \\
v_{m}=\left[v_{m i}\right]\{\bar{z}\} \\
w_{n}=w_{n 0}
\end{array}\right\} \quad i=0,1,2,3 .
$$

Here, the terms $\left[u_{l i}\right]=\left[\begin{array}{llll}u_{l 0} & u_{l 1} & u_{l 2} & u_{l 3}\end{array}\right],\left[v_{m i}\right]$ $=\left[\begin{array}{llll}v_{m 0} & v_{m 1} & v_{m 2} & v_{m 3}\end{array}\right]$, and $w_{n 0}$ represent the midplane deflections and are obtained from the Taylor series expansion of $u_{l}, v_{m}, w_{n}$, respectively, and $\{\bar{z}\}=\left[\begin{array}{cccc}1 & z & z^{2} & z^{3}\end{array}\right]^{T}$. The terms $u_{l 0}, v_{m 0}$, and $w_{n 0}$ corresponding to $i=0$ are the midplane displacements in $x, y$, and $z$ directions, respectively. The terms $u_{l 1}$ and $v_{m 1}$ corresponding to $i=1$ represent the rotation of the transverse normal to the midplane about $y$ and $x$-axes, respectively. The terms corresponding to $i=2$ and 3 are the same as the coefficients of $z^{2}$ and $z^{3}$, respectively.

The stress-strain relation for any lamina having the fibers oriented at an angle $\theta_{p l y}$ with reference to the principal material axes can be expressed as:

$$
\{\sigma\}=[\bar{Q}]\{\varepsilon\},
$$

where $\{\sigma\},[\bar{Q}]$, and $\{\varepsilon\}$ are the stress tensor, reduced stiffness matrix, and strain tensors, respectively. 


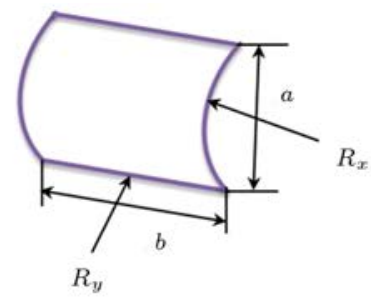

(a) Cylindrical: $R_{x}=R, R_{y}=\infty$

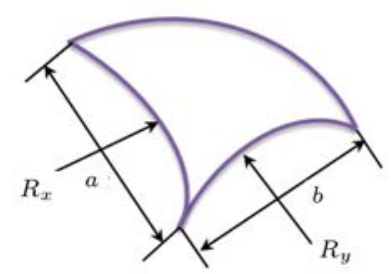

(d) Spherical: $R_{x}=R_{y}=R$

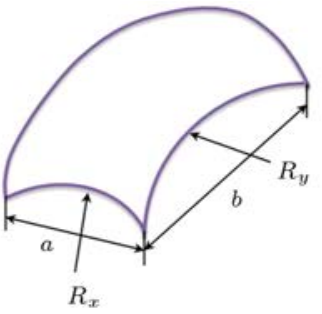

(b) Elliptical: $R_{x}=R, R_{y}=2 R$

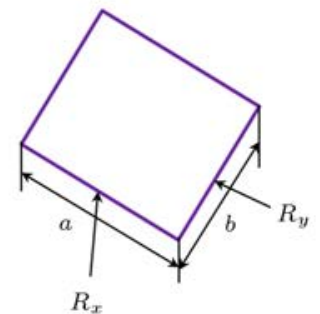

(c) Flat: $R_{x}=R_{y}=\infty$

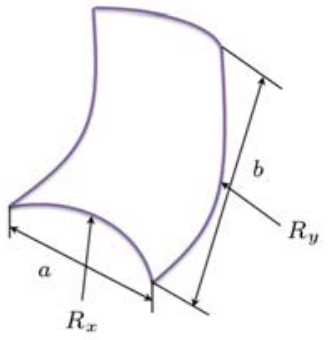

(e) Hyperboloid: $R_{x}=+R, R_{y}=-R$

Figure 2. Curved shell panel shapes.

$$
\begin{aligned}
& \{\varepsilon\}=\left\{\begin{array}{lllll}
\varepsilon_{x x} & \varepsilon_{y y} & \varepsilon_{x y} & \varepsilon_{x z} & \varepsilon_{y z}
\end{array}\right\}^{T} \\
& =\left\{\left(\frac{\partial u_{l}}{\partial x}+\frac{w_{n}}{R_{x}}\right) \quad\left(\frac{\partial v_{m}}{\partial y}+\frac{w_{n}}{R_{y}}\right) \quad\left(\frac{\partial u_{l}}{\partial y}+\frac{\partial v_{m}}{\partial x}+\frac{2 w_{n}}{R_{x y}}\right) \quad\left(\frac{\partial u_{l}}{\partial z}+\frac{\partial u_{m}}{\partial x}-\frac{u_{l}}{R_{x}}\right) \quad\left(\frac{\partial v_{m}}{\partial z}+\frac{\partial w_{n}}{\partial y}-\frac{v_{m}}{R_{y}}\right)\right\}^{T} .
\end{aligned}
$$

Box I

The strain vector of the laminated shell panel can be expressed by Eq. (3) as shown in Box I [50]. The stress vector is formulated as:

$$
\{\sigma\}=[D]\{\varepsilon\} .
$$

The elements of the stiffness matrix $[D]$ are defined as:

$$
[D]=\sum_{k=1}^{n} \int_{z k-1}^{z k}\left(\bar{Q}_{i j}\right)_{k}\left(1, z, z^{2} \cdots z^{6}\right) d z .
$$

The numerical solution for the flexure of the curved hybrid laminated composite shell panels is obtained via Finite Element Method (FEM). The panel model was discretized using a nine-noded isoparametric Lagrangian element (for element details refer to [51]). Each node of the element has nine degrees of freedom in agreement with the displacement model given by Eq. (1). The deflection $(\delta)$ of a point lying on the mid-surface can be interpolated using the nodal shape function $\left(N_{i}\right)$ in terms of the nodal deflection $\left(\delta_{i}\right)$ of the $i$ th node as:

$$
\delta=\sum_{i=1}^{n} N_{i}(x, y) \delta_{i}
$$

The strain vector represented by Eq. (3) was splitted into the product of the strain interpolation matrix $\left[Z_{e}\right]$ (interpolates strain over thickness) and the mid-plane strains $\{\bar{\varepsilon}\}$ as:

$$
\{\varepsilon\}=\left[Z_{e}\right]\{\bar{\varepsilon}\} .
$$

The mid-plane strain vector $\{\bar{\varepsilon}\}$ can be decomposed as the product of the mid-plane deflection $\delta$ and the matrix of the partially differentiated shape functions $\left[D_{L}\right]$ as:

$$
\{\bar{\varepsilon}\}=\left[D_{L}\right]\{\delta\} \text {. }
$$

Eq. (1) is now represented in discrete form as:

$$
\{\bar{\delta}\}=\left\{\begin{array}{l}
u_{l} \\
v_{m} \\
w_{n}
\end{array}\right\}=\left[Z_{d}\right]\{\delta\} .
$$

Here, the matrix $\left[Z_{d}\right]$ interpolates deflection over the thickness coordinate.

The strain energy $(U)$ of the hybrid laminated composite panel is given as [50]:

$$
U=\frac{1}{2} \int_{V}\{\varepsilon\}^{T}\{\sigma\} d V=\frac{1}{2} \iint\left[\int_{-h / 2}^{+h / 2}\{\varepsilon\}^{T}\{\sigma\} d z\right] d x d y .
$$

Eq. (10) can be further rewritten by substituting it into 
Eqs. (5) and (8) as:

$$
\begin{aligned}
U & =\frac{1}{2} \iint\left(\{\bar{\varepsilon}\}^{T}[\Lambda]\{\bar{\varepsilon}\}\right) d x d y \\
& =\frac{1}{2} \iint\left(\{\delta\}_{i}^{T}\left[D_{L}\right]_{i}^{T}[\Lambda]\left[D_{L}\right]_{i}\{\delta\}_{i}\right) d x d y
\end{aligned}
$$

where:

$$
[\Lambda]=\int_{-h / 2}^{+h / 2}\left[Z_{e}\right]^{T}[\bar{Q}]\left[Z_{e}\right] d z .
$$

The total work done by an externally applied load, $F$, is given by:

$$
W=\int\{\delta\}^{T}\{F\} d A .
$$

The stiffness of the panel can be expressed in matrix $[K]$ form as $[50]$ :

$$
[K]=\int_{A}\left(\sum_{k=1}^{n} \int_{z_{k-1}}^{z_{k}}\left[D_{L}\right]^{T}[\Lambda]\left[D_{L}\right] d z\right) d A .
$$

The mathematical equation required bending analysis is given by the relation:

$$
\partial \Pi=\partial(U-W)=0,
$$

where $\partial$ is the variational symbol and $\Pi$ is the total energy functional.

Now, the final form of the equation of equilibrium for the transversely deflected composite shell panel is given by the following equations:

$$
[K]\{\delta\}=\{F\}
$$

where $[K]$ and $\{F\}$ are the global system stiffness matrix and load vectors, respectively. The detailed expression for obtaining bending deflection and bending stress can be referred from Hirwani et al. [36].

\section{Numerical results and discussion}

The HSDT based numerical scheme is now implemented to analyze the flexural responses of curved laminated composite shell panels. An FE code has been developed in MATLAB for the present analysis. Firstly, the convergence of the flexural responses (central deflection, normal and transverse shear stress) predicted by the above mentioned scheme is ensured. Also, the accuracy of the predicted responses is justified by comparing the present results with the standard results presented in the previous studies. Finally, the effect of material property and geometrical parameters on the nondimensional central deflection and stress responses of the hybrid laminated composite panels are computed and discussed in detail. Table 1 lists the material properties [50] (used in the present analysis) of the hybrid composite flat panels fabricated by typical hand lay-up technique at NIT Rourkela and tested at CIPET, LARPM, Bhubaneswar.

It is assumed that the curved laminated composite shell panels were subjected to the following types of mechanical loading (pictorially depicted in Figure 3):

- UDL is given by:

$$
p(x, y)=q_{0} ;
$$

- SDL is given by:

$$
q=q_{0} \sin \left(\frac{\pi x}{a}\right) \sin \left(\frac{\pi y}{b}\right) .
$$

The maximum central deflection $w_{c}$ of the panels was nondimensionalized as $\bar{w}=\frac{w_{c}}{h}$, where, $h$ is the thickness of the panel.

The nondimensional form of normal stresses and shear stresses are given as:

$$
\overline{\sigma_{x}}=\sigma_{x}\left(\frac{h^{2}}{q_{0} a^{2}}\right), \quad \overline{\sigma_{y}}=\sigma_{y}\left(\frac{h^{2}}{q_{0} a^{2}}\right),
$$

and:

$$
\overline{\tau_{x z}}=\tau_{x z}\left(\frac{h^{2}}{q_{0} a^{2}}\right) .
$$

Table 1. Material properties of hybrid composite laminates.

\begin{tabular}{lccccc}
\hline \multicolumn{1}{c}{ Material properties } & $\mathbf{4 C}$ & $\mathbf{3 G 1 C}$ & $\mathbf{2 G} \mathbf{2 C}$ & $\mathbf{2 G 1 C 1 K}$ & $\mathbf{4 K}$ \\
\hline Young's modulus, $E_{1}=E_{2}=E_{3}(\mathrm{GPa})$ & 13.549 & 10.710 & 13.289 & 11.082 & 8.491 \\
Shear modulus, $G_{12}=G_{13}(\mathrm{GPa})$ & 5.376 & 4.284 & 5.316 & 4.433 & 3.396 \\
Shear modulus, $G_{23}(\mathrm{GPa})$ & $0.5 G_{12}$ & $0.5 G_{12}$ & $0.5 G_{12}$ & $0.5 G_{12}$ & $0.5 G_{12}$ \\
Poisson's ratio, $\nu_{12}=\nu_{23}=\nu_{13}$ & 0.26 & 0.25 & 0.25 & 0.25 & 0.25 \\
Density, $\rho\left(\mathrm{kg} / \mathrm{m}^{3}\right)$ & 1394 & 1579 & 1524 & 1500 & 1000 \\
\hline
\end{tabular}




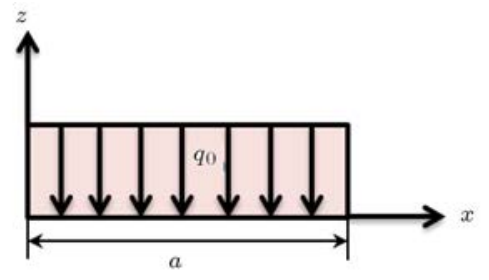

(a)
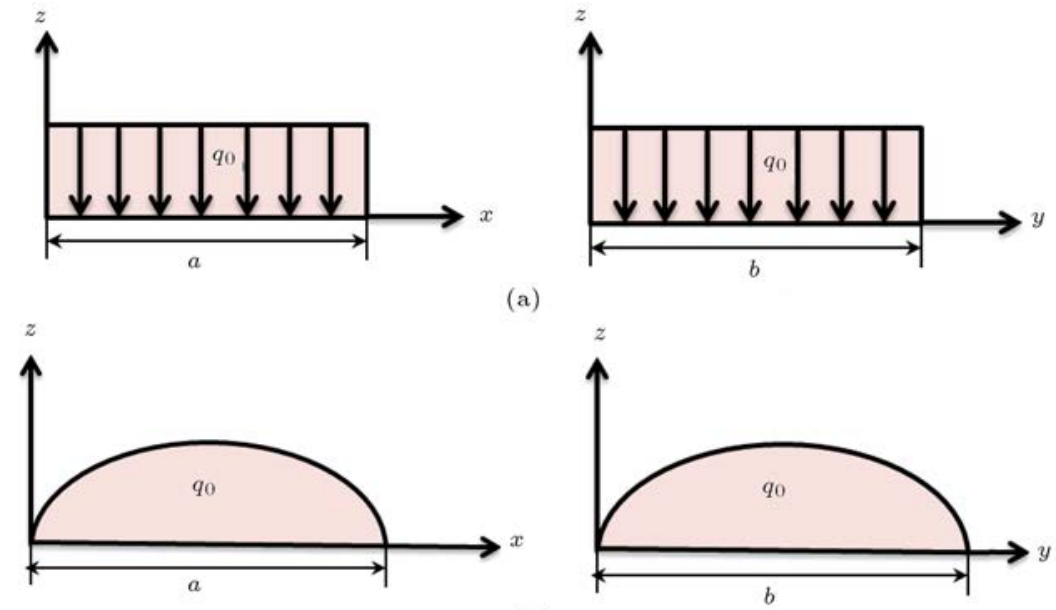

(b)

Figure 3. Types of mechanical loading: (a) Uniformly Distributed Load (UDL) and (b) Sinusoidal Distributed Load (SDL).

The coordinates for the maximum value of stresses for the present evaluation are as follows:

- In-plane normal stress $\left(\sigma_{x}\right)=(a / 2, b / 2, \pm h / 2)$;

- In-plane normal stress $\left(\sigma_{y}\right)=(a / 2, b / 2, \pm h / 2)$;

- In-plane shear stress $\left(\tau_{x z}\right)=(0, b / 2, \pm h / 2)$.

The different edge conditions that are employed to avoid the rigid body motion for the computation of the numerical responses, can be referred from Hirwani et al. [36].

\subsection{Convergence and validation study}

3.1.1. Convergence and validation of nondimensional central deflection

Firstly, the convergence of the present responses is confirmed by computing the nondimensional central deflection $\bar{w}=\left(w_{c} E_{2} h^{3} / q_{0} a^{4}\right) \times 10^{3}$ for increasing mesh density. An example of a simply supported four-layered symmetric cross-ply laminated composite $\left[0^{\circ} / 90^{\circ}\right]_{\mathrm{s}}$ spherical shell panel subjected to UDL and SDL which is presented by Reddy and Liu [33] was solved for the comparison purpose. Table 2 illustrates the present values alongside the reference values. The

Table 2. Convergence and validation of nondimensional central deflection $\bar{w}=\left(w_{c} E_{2} h^{3} / q_{0} a^{4}\right) \times 10^{3}$ of cross-ply laminated spherical shells under Uniformly Distributed Load (UDL) and Sinusoidally Distributed Load (SDL) ( $E_{1}=25 E_{2}$, $\left.G_{12}=G_{13}=0.5 E_{2}, G_{23}=0.2 E_{2}, \nu=0.25, a / b=1, R / a=100, a / h=10,0^{\circ} / 90^{\circ} / 0^{\circ}, q_{0}=100\right)$.

\begin{tabular}{|c|c|c|c|c|}
\hline \multirow[t]{2}{*}{ Mesh size } & \multicolumn{2}{|c|}{$\begin{array}{l}\text { Nondimensional central } \\
\text { deflection }(a / h=10)\end{array}$} & \multicolumn{2}{|c|}{$\begin{array}{l}\text { Nondimensional central } \\
\text { deflection }(a / h=100)\end{array}$} \\
\hline & UDL & SDL & UDL & SDL \\
\hline $2 \times 2$ & 14.3592 & 8.5065 & 7.6339 & 4.4448 \\
\hline $4 \times 4$ & 11.8426 & 7.7272 & 7.0869 & 4.5393 \\
\hline $5 \times 5$ & 11.1217 & 7.2658 & 6.6838 & 4.3065 \\
\hline $6 \times 6$ & 11.1213 & 7.2530 & 6.7341 & 4.3367 \\
\hline $7 \times 7$ & 11.1526 & 7.2811 & 6.7504 & 4.3567 \\
\hline $8 \times 8$ & 11.1407 & 7.2683 & 6.7601 & 4.3644 \\
\hline $9 \times 9$ & 11.1544 & 7.2821 & 6.7631 & 4.3706 \\
\hline Reddy and Liu [33] & 10.8980 & 7.1240 & 6.6496 & 4.3074 \\
\hline
\end{tabular}


present flexural responses were thus found to converge well with the mesh refinement. Therefore, a $(6 \times 6)$ mesh is adopted for computational purpose in the following analyses. Moreover, it is worthy to note that present values corresponding to a mesh of $(6 \times 6)$ were in fine agreement with the values reported by Reddy and Liu [33] emphasizing the efficacy of the proposed scheme in predicting the flexural responses.

Additionally, to ensure the accuracy of the present flexural responses, more examples of the simply supported composite spherical shell panels with different lay-up sequences such as $\left[0^{\circ} / 90^{\circ}\right],\left[0^{\circ} / 90^{\circ} / 0^{\circ}\right]$, and $\left[0^{\circ} / 90^{\circ}\right]_{\mathrm{s}}$ and varying curvature ratio subjected to UDL and SDL were solved. Tables 3 and 4 present a compar- ison of present nondimensional central defection with the values obtained by Reddy and Liu [33] using First order Shear Deformation Theory (FSDT)and HSDT. The results indicated a close agreement between the present and the reference values thereby confirming the validity of the present method.

\subsubsection{Validation of bending stress}

Similarly, the present bending stress has been validated by solving an example of a simply supported threelayered $\left[0^{\circ} / 90^{\circ} / 0^{\circ}\right]$ square plate subjected to SDL as pointed out by Kant and Swaminathan [52]. The nondimensional normal stresses $\left(\overline{\sigma_{x}}\right.$ and $\left.\bar{\sigma}_{y}\right)$ are presented in Figure 4(a) and (b), respectively. The stress

Table 3. Validation of nondimensional central deflections $\bar{w}=\left(w_{c} E_{2} h^{3} / q_{0} a^{4}\right) \times 10^{3}$ of cross-ply laminated spherical shells under Uniformly Distributed Load (UDL) and Sinusoidally Distributed Load (SDL) $(a / h=10)\left(E_{1}=25 E_{2}\right.$, $\left.G_{12}=G_{13}=0.5 E_{2}, G_{23}=0.2 E_{2}, \nu=0.25, a / b=1, q_{0}=100\right)$.

\begin{tabular}{|c|c|c|c|c|c|c|c|}
\hline \multirow{4}{*}{$\begin{array}{c}\text { Curvature } \\
\text { ratio } \\
(R / a)\end{array}$} & \multirow[b]{4}{*}{ Theory } & \multicolumn{6}{|c|}{ Nondimensional central deflection $\left(\bar{w}=w_{c} / h\right)$} \\
\hline & & \multicolumn{3}{|c|}{$\mathrm{UDL}, a / h=10$} & \multicolumn{3}{|c|}{$\mathrm{SDL}, a / h=10$} \\
\hline & & \multicolumn{6}{|c|}{ Lamination scheme } \\
\hline & & $0^{\circ} / 90^{\circ}$ & $0^{\circ} / 90^{\circ} / 0^{\circ}$ & {$\left[0^{\circ} / \mathbf{9 0}^{\circ}\right]_{\mathrm{s}}$} & $0^{\circ} / 90^{\circ}$ & $0^{\circ} / 90^{\circ} / 0^{\circ}$ & {$\left[0^{\circ} / 90^{\circ}\right]_{\mathrm{s}}$} \\
\hline \multirow{3}{*}{5} & FSDT [33] & 19.944 & 9.7937 & 9.8249 & 11.429 & 6.425 & 6.362 \\
\hline & HSDT [33] & 17.566 & 10.332 & 10.476 & 11.166 & 6.768 & 6.786 \\
\hline & Present numerical (HSDT) & 17.966 & 10.615 & 10.753 & 11.415 & 6.935 & 6.950 \\
\hline \multirow{3}{*}{10} & FSDT [33] & 19.065 & 10.11 & 10.141 & 12.123 & 6.624 & 6.559 \\
\hline & HSDT [33] & 18.744 & 10.752 & 10.904 & 11.896 & 7.032 & 7.053 \\
\hline & Present numerical (HSDT) & 19.086 & 10.991 & 11.138 & 12.108 & 7.171 & 7.189 \\
\hline \multirow{3}{*}{20} & FSDT [33] & 19.365 & 10.191 & 10.222 & 12.309 & 6.675 & 6.609 \\
\hline & HSDT [33] & 19.064 & 10.862 & 11.017 & 12.094 & 7.101 & 7.123 \\
\hline & Present numerical (HSDT) & 19.390 & 11.089 & 11.239 & 12.296 & 7.233 & 7.252 \\
\hline \multirow{3}{*}{50} & FSDT [33] & 19.452 & 10.214 & 10.245 & 12.362 & 6.690 & 6.624 \\
\hline & HSDT [33] & 19.155 & 10.893 & 11.049 & 12.150 & 7.121 & 7.143 \\
\hline & Present numerical (HSDT) & 19.479 & 11.117 & 11.267 & 12.350 & 7.250 & 7.270 \\
\hline \multirow{3}{*}{ Plate } & FSDT [33] & 19.469 & 10.22 & 10.251 & 12.373 & 6.693 & 6.628 \\
\hline & HSDT [33] & 19.172 & 10.899 & 11.055 & 12.161 & 7.125 & 7.147 \\
\hline & Present numerical (HSDT) & 19.497 & 11.122 & 11.272 & 12.362 & 7.253 & 7.273 \\
\hline
\end{tabular}


Table 4. Nondimensional central deflections $\bar{w}=\left(w_{c} E_{2} h^{3} / q_{0} a^{4}\right) \times 10^{3}$ of cross-ply laminated spherical shells under Uniformly Distributed Load (UDL) and Sinusoidally Distributed Load (SDL) $(a / h=100)\left(E_{1}=25 E_{2}\right.$, $G_{12}=G_{13}=0.5 E_{2}, G_{23}=0.2 E_{2}, \nu=0.25, a / b=1, q_{0}=100$, SSSS $)$.

\begin{tabular}{|c|c|c|c|c|c|c|c|}
\hline \multirow{4}{*}{$\begin{array}{c}\text { Curvature } \\
\text { ratio } \\
(R / a)\end{array}$} & \multirow[b]{4}{*}{ Theory } & \multicolumn{6}{|c|}{ Nondimensional central deflection $\left(\bar{w}=w_{c} / h\right)$} \\
\hline & & \multicolumn{3}{|c|}{$\mathrm{UDL}, a / h=100$} & \multicolumn{3}{|c|}{$\mathrm{SDL}, a / h=100$} \\
\hline & & \multicolumn{6}{|c|}{ Lamination scheme } \\
\hline & & $0^{\circ} / 90^{\circ}$ & $0^{\circ} / 90^{\circ} / 0^{\circ}$ & {$\left[0^{\circ} / 90^{\circ}\right]_{\mathrm{s}}$} & $0^{\circ} / 90^{\circ}$ & $0^{\circ} / 90^{\circ} / 0^{\circ}$ & {$\left[0^{\circ} / 90^{\circ}\right]_{\mathrm{s}}$} \\
\hline & FSDT [33] & 1.753 & 1.511 & 1.5358 & 1.194 & 1.033 & 1.027 \\
\hline 5 & HSDT [33] & 1.751 & 1.509 & 1.5332 & 1.193 & 1.032 & 1.026 \\
\hline & Present numerical (HSDT) & 1.771 & 1.523 & 1.5496 & 1.194 & 1.035 & 1.030 \\
\hline & FSDT [33] & 5.542 & 3.644 & 3.7208 & 3.576 & 2.410 & 2.403 \\
\hline 10 & HSDT [33] & 5.538 & 3.642 & 3.7195 & 3.573 & 2.409 & 2.402 \\
\hline & Present numerical (HSDT) & 5.574 & 3.684 & 3.7575 & 3.573 & 2.421 & 2.413 \\
\hline & FSDT [33] & 11.273 & 5.547 & 5.6618 & 7.127 & 3.615 & 3.610 \\
\hline 20 & HSDT [33] & 11.268 & 5.550 & 5.666 & 7.123 & 3.617 & 3.613 \\
\hline & Present numerical (HSDT) & 11.302 & 5.618 & 5.7243 & 7.117 & 3.639 & 3.634 \\
\hline & FSDT [33] & 15.714 & 6.482 & 6.6148 & 9.871 & 4.202 & 4.201 \\
\hline 50 & HSDT [33] & 15.711 & 6.489 & 6.6234 & 9.869 & 4.207 & 4.207 \\
\hline & Present numerical (HSDT) & 15.734 & 6.571 & 6.6925 & 9.853 & 4.235 & 4.233 \\
\hline & FSDT [33] & 16.645 & 6.642 & 6.7772 & 10.446 & 4.302 & 4.302 \\
\hline 100 & HSDT [33] & 16.642 & 6.649 & 6.7866 & 10.444 & 4.307 & 4.308 \\
\hline & Present numerical (HSDT) & 16.662 & 6.734 & 6.8576 & 10.426 & 4.336 & 4.336 \\
\hline & FSDT [33] & 16.98 & 6.697 & 6.8331 & 10.653 & 4.337 & 4.336 \\
\hline Plate & HSDT [33] & 16.977 & 6.704 & 6.8427 & 10.651 & 4.342 & 4.343 \\
\hline & Present numerical (HSDT) & 16.997 & 6.790 & 6.9145 & 10.632 & 4.3716 & 4.371 \\
\hline
\end{tabular}




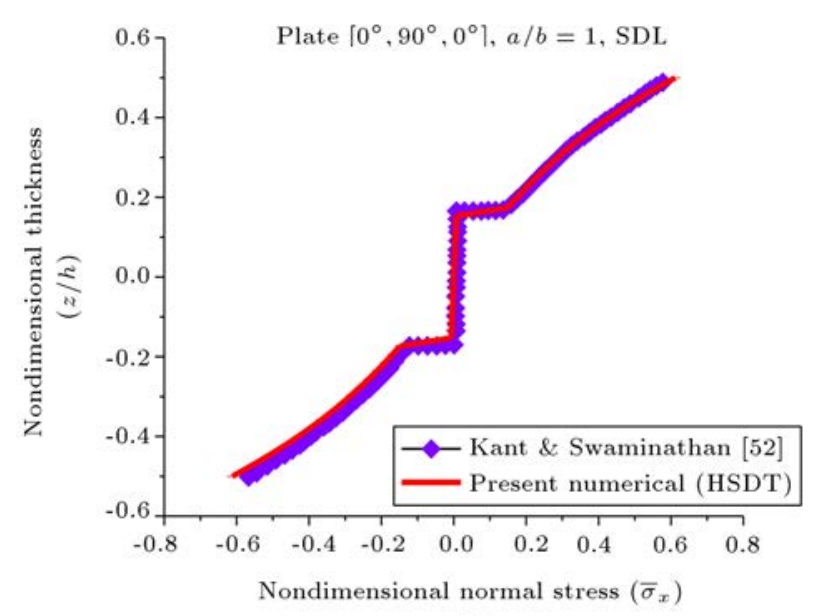

(a)

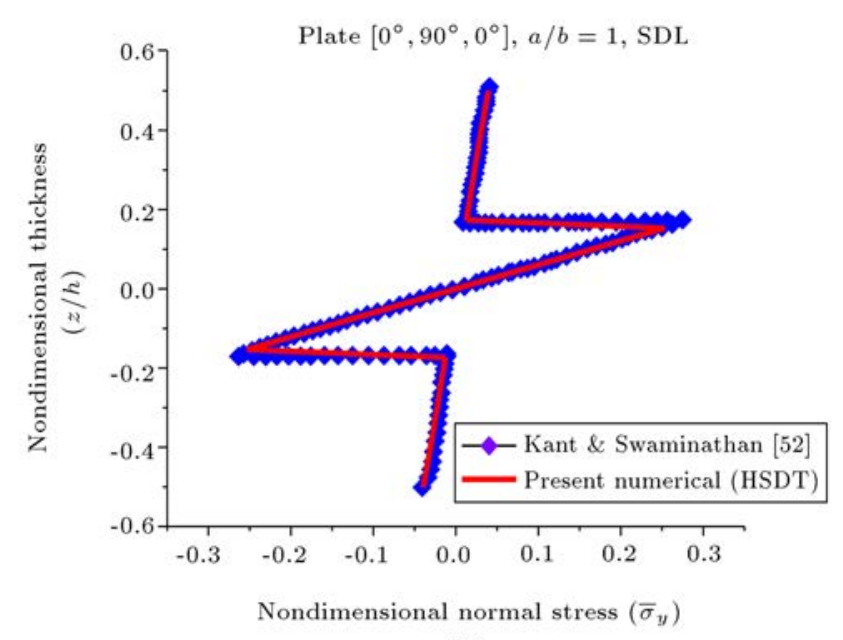

(b)

$$
\left(E_{1} / E_{2}=25, E_{2}=E_{3}=7 \mathrm{GPa}, G_{12}=G_{13}=0.5 E_{2},\right.
$$$$
\left.G_{23}=0.2 E_{2}, \nu_{12}=\nu_{23}=\nu_{13}=0.25[52]\right)
$$

Figure 4. Validation of nondimensional in-plane normal stress $\overline{\sigma_{x}}(\mathrm{a})$ and $\overline{\sigma_{y}}$ (b) through the nondimensional thickness $(z / h)$ of simply supported square plate of three layers $\left(0^{\circ} / 90^{\circ} / 0^{\circ}\right)$ under sinusoidally distributed transverse load.

responses obtained using the mentioned model were close to the reference, thus justifying the efficacy of the present model for obtaining the bending stress responses.

\subsection{Numerical examples}

The nondimensional central deflection and normal and transverse shear stress developed in curved hybrid composite shell panels were analyzed via the present FE implementation of higher-order kinematics displacement. The structural parameters, specifically the thickness ratio $(a / h)$, aspect ratio $(a / b)$, support conditions, geometry, curvature ratio $(R / a)$, and hybrid types were examined to study their impact on the central deflections and stresses of the hybrid curved composite shell panels. The material properties (for four-layered antisymmetric $\left(0^{\circ} / 90^{\circ} / 0^{\circ} / 90^{\circ}\right)$ cross-ply) used in the present analysis are listed in Table 1 . The support conditions considered in the present analysis are taken from the reference [36].

\subsubsection{Effect of thickness ratio $(a / h)$ on flexural flat plate}

The effect of thickness ratios $(a / h)$, i.e. width to thickness $(a / h=5,10,20,40,60,80,100)$ of the nondimensional central deflections on the bending responses of the laminated hybrid composite plate (4C) subjected to UDL and SDL are computed via the present formulation and the results are illustrated in Figure 5(a) and (b), respectively. The nondimensional central deflections increased with the increase of thickness ratio and the load. It is due to the fact that by decreasing the thickness while keeping the length constant, the

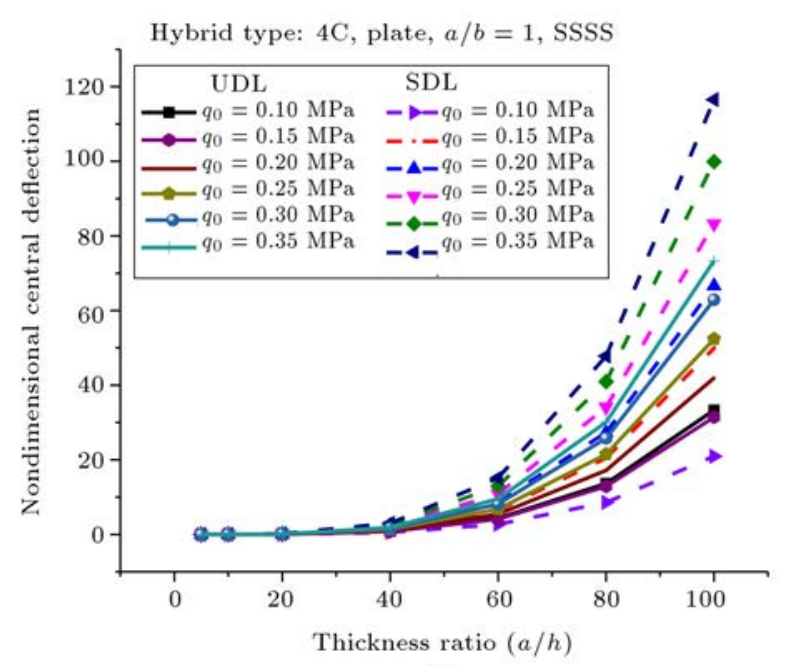

(a)

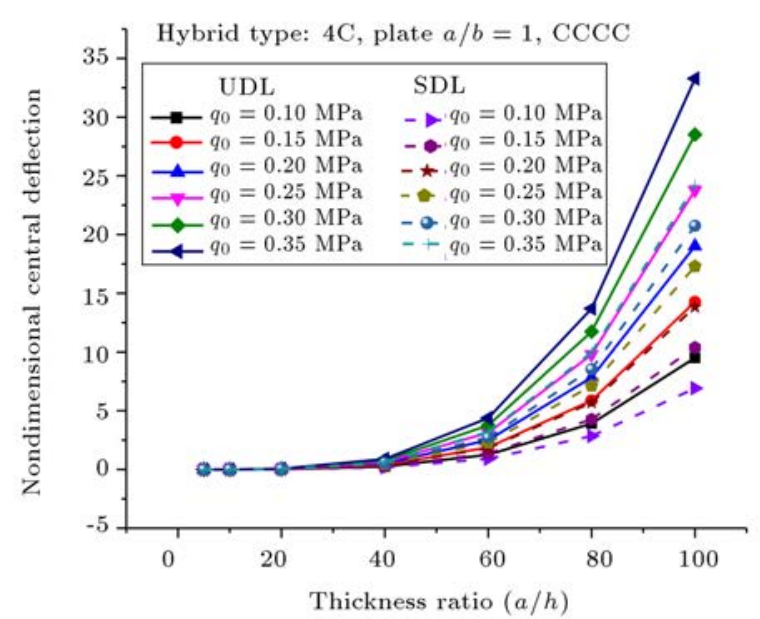

(b)

Figure 5. Nondimensional central deflection of the flat shell panel for different thickness ratio under Uniformly Distributed Load (UDL) and Sinusoidally Distributed Load (SDL) with two different support conditions: (a) SSSS and (b) CCCC. 
structure became thin leading to a decrease in its stiffness as the stiffness is directly proportional to the thickness. But, for all edge clamped conditions, the nondimensional central deflection was more under UDL than SDL as shown in Figure 5(b). The reverse state was observed for the simply supported case in which the nondimensional central deflections were more under SDL than UDL, as shown in Figure 5(a).

Similarly, the thickness ratio varied as $a / h=5$, $10,20,50,100$ and its effect on the nondimensional stresses $\overline{\sigma_{x}}, \overline{\sigma_{y}}$, and $\overline{\tau_{x z}}$ developed in the simply supported hybrid composite (4C) square plate subjected to SDL of 0.20 MPa magnitude, is investigated the results of which are presented in Figure 6(a), (b), and (c) respectively. It is observed from Figure 6(a) and (b) that the, nondimensional normal stresses $\left(\overline{\sigma_{x}}, \overline{\sigma_{y}}\right)$ increased with the increase of nondimensional thickness, also it was found that the normal stresses follow an approximately similar trend for all the values of thickness ratios (i.e., 5, 10, 20, 50, 100). However, the shear stress decreased as the thickness ratio increased as is evident from Figure 6(c).

\subsubsection{Effect of aspect ratio $(a / b)$ on the flexural behaviour}

The aspect ratio varied as $a / b=0.5,0.8,1.1,1.4$, $1.7,2.0$, and its effect on the nondimensional central deflection of the hybrid composite plate $3 \mathrm{G}-1 \mathrm{C}$ under two types of loading (UDL and SDL) was studied using the proposed model and the results are presented in Figure 7(a) and (b), respectively. From Figure 7, it is observed that the nondimensional central deflection decreased with the increase of the aspect ratio. This is due to the fact that as the aspect ratio increases the stiffness of the plate decreases. Also, it is evident from the figure that the central deflection was higher when all the edges were simply supported (SSSS) compared to the case in which all edges are clamped (CCCC). The deflection had a higher value in the case of UDL than SDL for both the SSSS and CCCC type.

Also, the nondimensional stresses $\overline{\sigma_{x}}, \overline{\sigma_{y}}$ and $\overline{\tau_{x z}}$ for the clamped hybrid laminated composite (3G-1C) square plate under SDL of $0.15 \mathrm{MPa}$ magnitude are computed using the model under discussion for varying thickness ratios $(a / b=0.5,0.8,1.1,1.4,1.7,2.0)$ and the results are presented in Figure 8(a), (b), and (c), respectively.

As can be observed from Figure $8(\mathrm{a})$ and (b), the nondimensional normal stresses $\left(\overline{\sigma_{x}}, \overline{\sigma_{y}}\right)$ increased with the increase of nondimensional thickness. Also, the magnitude of normal stresses decreased with an increase of the aspect ratio because of a decrease in the stiffness of the plate. The variation of normal stresses between the top and bottom was greater in the case of lower aspect ratios. The nondimensional shear stress
Hybrid type: $4 \mathrm{C}$, plate $a / b=1$, SSSS $q_{0}=0.20 \mathrm{MPa}, \mathrm{SDL}$

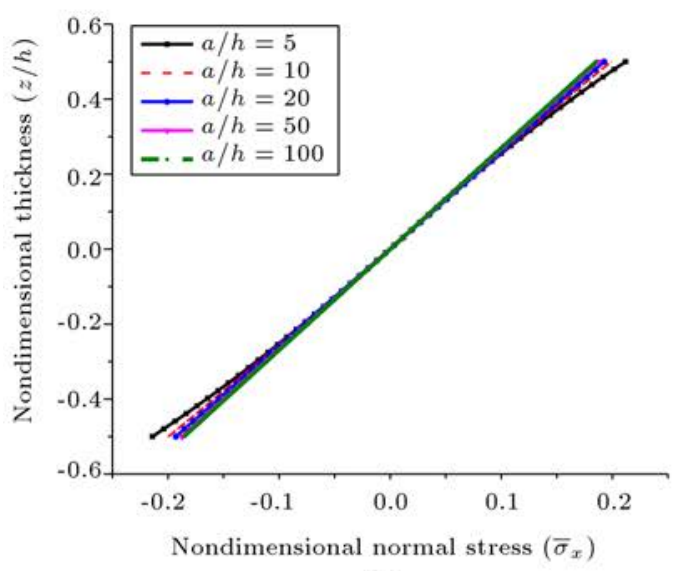

(a)

Hybrid type: $4 \mathrm{C}$, plate $a / b=1$, SSSS $q_{0}=0.20 \mathrm{MPa}, \mathrm{SDL}$

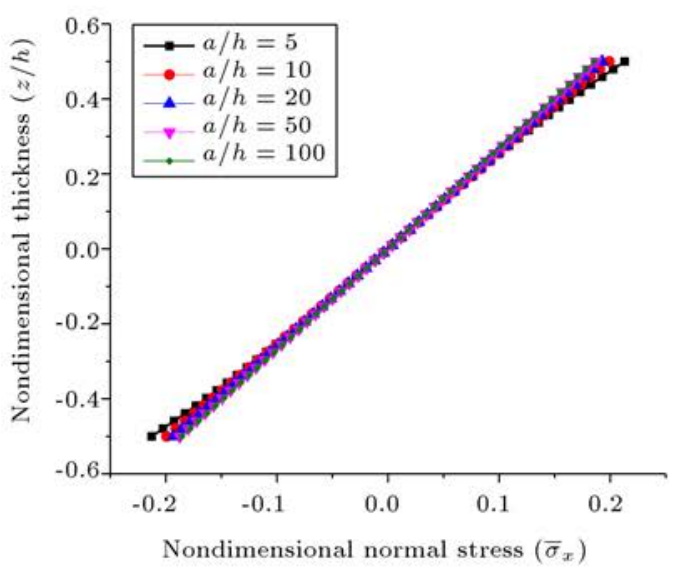

(b)

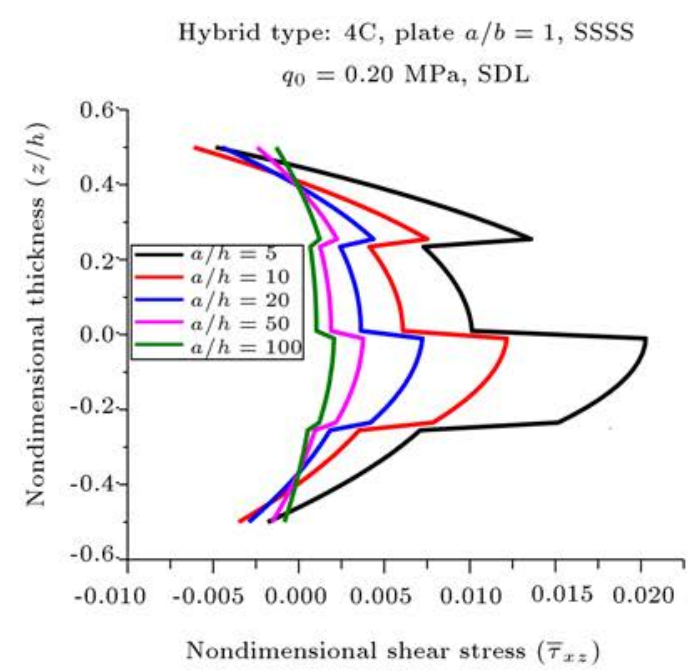

(c)

Figure 6. Variation of in-plane nondimensional stresses through the thickness of four-layered $4 \mathrm{C}$ hybrid simply supported square plate under sinusoidal transverse load: (a) $\left(\overline{\sigma_{x}}\right)$, (b) $\left(\bar{\sigma}_{y}\right)$, and (c) $\left(\overline{\tau_{x z}}\right)$. 
Hybrid type: $3 \mathrm{G} 1 \mathrm{C}$, plate $a / h=50$, SSSS

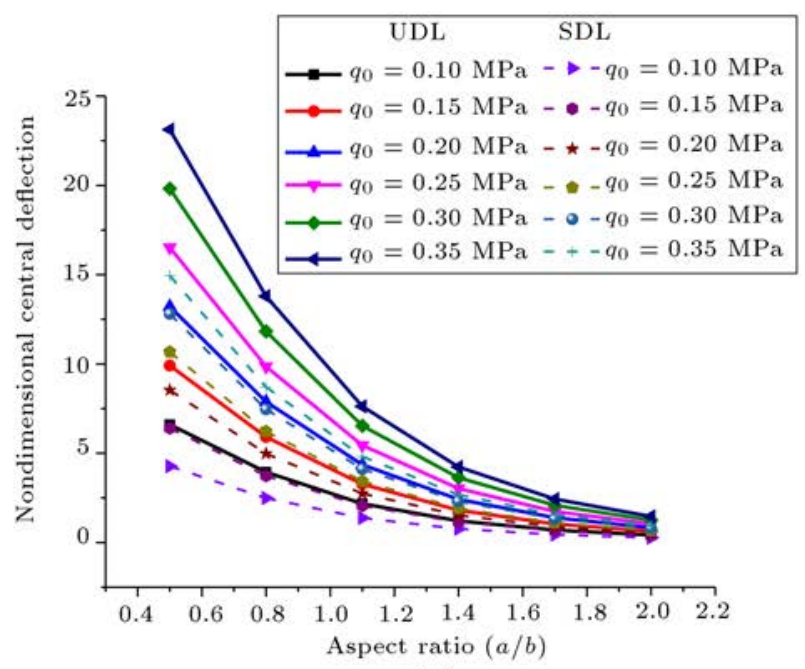

(a)

Hybrid type: $3 \mathrm{G} 1 \mathrm{C}$, plate $a / h=50$, SSSS

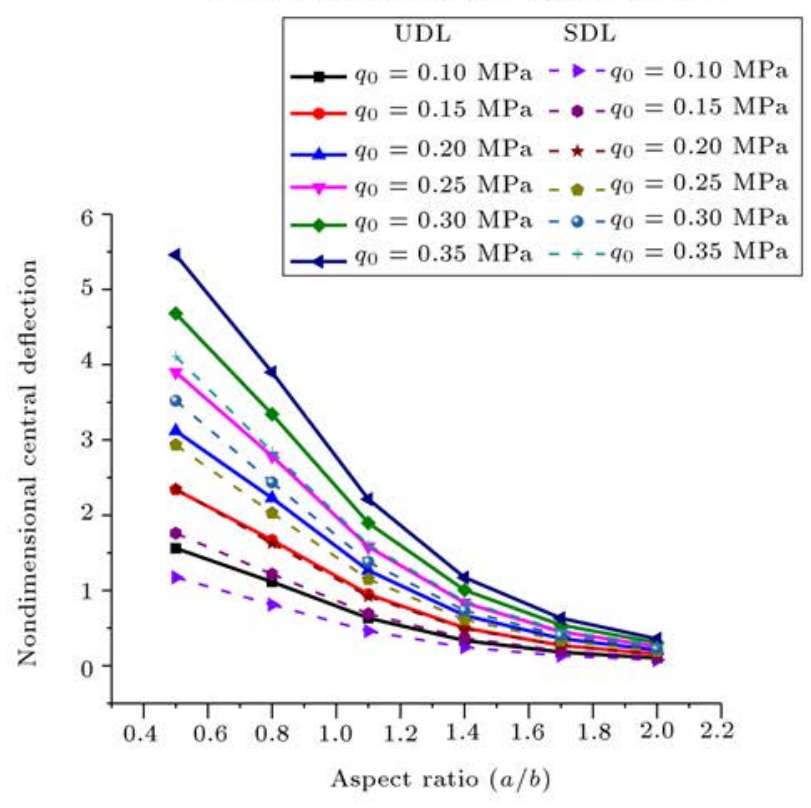

(b)

Figure 7. Nondimensional central deflection of the flat shell panel for different aspect ratio under Uniformly Distributed Load (UDL) and Sinusoidally Distributed Load (SDL) with two different support conditions: (a) SSSS and (b) CCCC.

increased with the increase of aspect ratio, as is clear from Figure 8(c).

\subsubsection{Effect of geometry on the flexural behaviour}

Figure 9(a) and (b) show the nondimensional central deflections with varying geometry (plate, cylindrical, spherical, hyperboloid, and elliptical) and load intensity $\left(q_{0}=0.10,0.15,0.20,0.25,0.30\right.$, and $\left.0.35 \mathrm{MPa}\right)$ for a simply supported (SSSS) and fully clamped (CCCC) 2G-1C-1K hybrid laminated composite square
Hybrid type: 3G1C, plate $a / h=50, \mathrm{CCCC}$ $q_{0}=0.15 \mathrm{MPa}, \mathrm{SDL}$

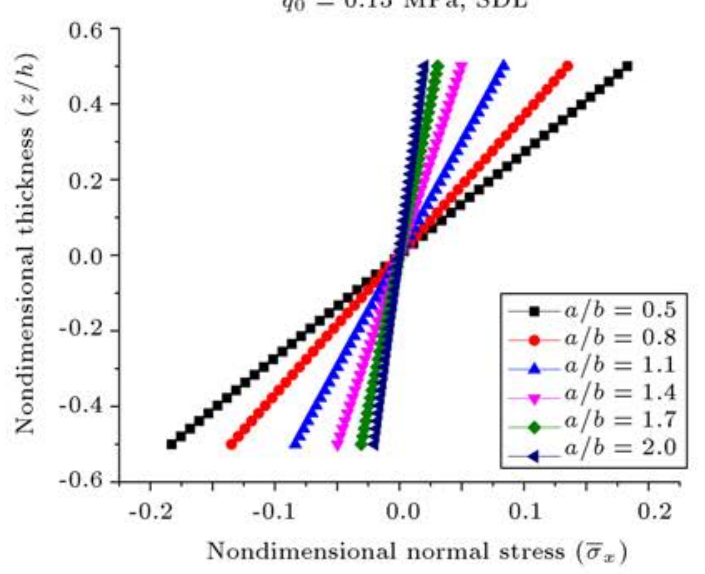

(a)

Hybrid type: $3 \mathrm{G} 1 \mathrm{C}$, plate $a / h=50$, CCCC $q_{0}=0.15 \mathrm{MPa}, \mathrm{SDL}$

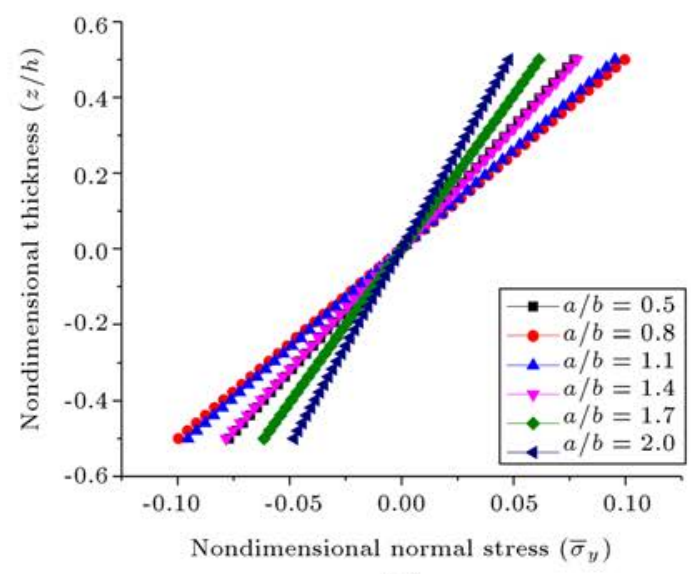

(b)

Hybrid type: $3 \mathrm{G} 1 \mathrm{C}$, plate $a / h=50$, CCCC $q_{0}=0.15 \mathrm{MPa}, \mathrm{SDL}$

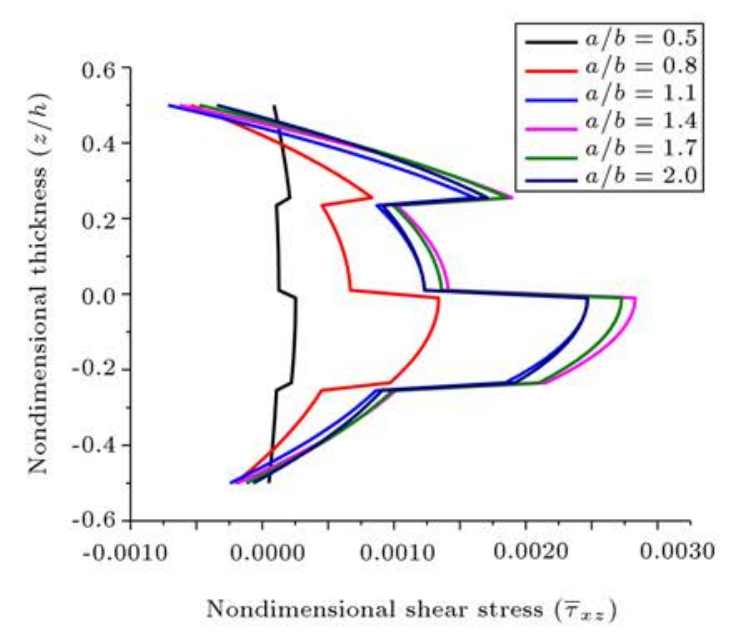

(c)

Figure 8. Variation of in-plane nondimensional stresses through the thickness of four-layered 3G-1C hybrid clamped square plate under sinusoidal transverse load: (a) $\left(\overline{\sigma_{x}}\right)$, (b) $\left(\overline{\sigma_{y}}\right)$, and (c) $\left(\overline{\tau_{x z}}\right)$. 
Hybrid type: $2 \mathrm{G} 1 \mathrm{C} 1 \mathrm{~K}, a / b=1, a / h=50, R / a=50$, SSSS

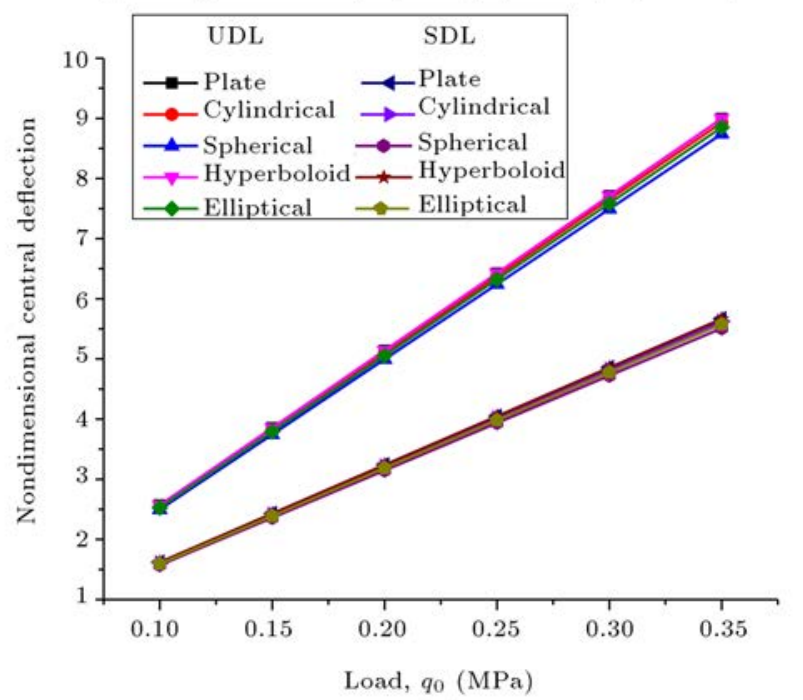

(a)

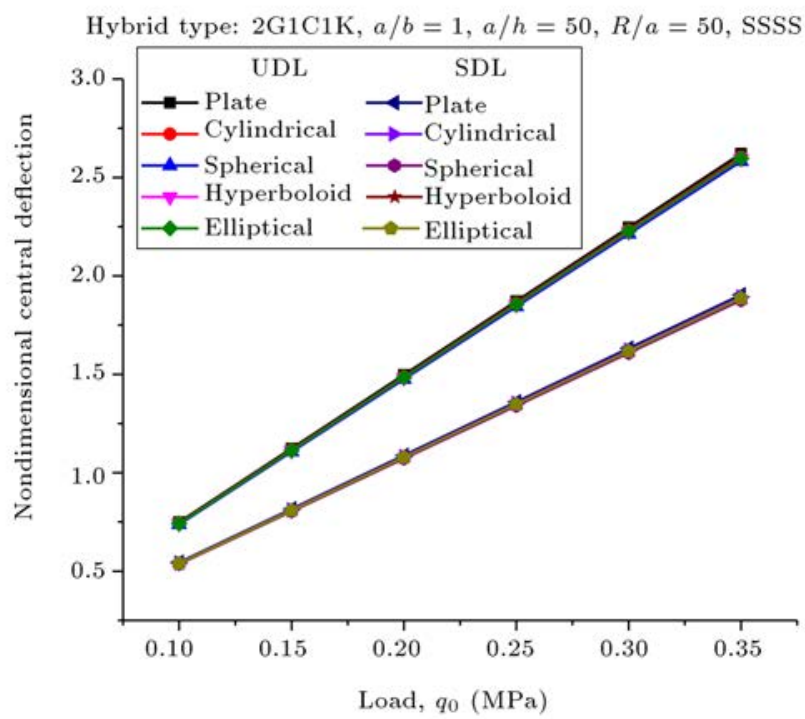

(b)

Figure 9. Nondimensional central deflection for different geometries under Uniformly Distributed Load (UDL) and Sinusoidally Distributed Load (SDL) with different support conditions: (a) SSSS and (b) CCCC.

shell panel subjected to both UDL and SDL. It was observed that the deflection was not much affected by the change in geometry with a variation of load. The deflection increased as the load increased. The deflection was higher in the case of simply supported panels as compared to all edges clamped condition. Also, the deflection was higher for the SDL condition as compared to that under the UDL condition.

A similar trend is observed in the variation of normal and shear stresses. Both the normal stress and shear stress values were approximately the same for all types of geometry at a specified load as shown in Figure 10(a), (b) and (c).

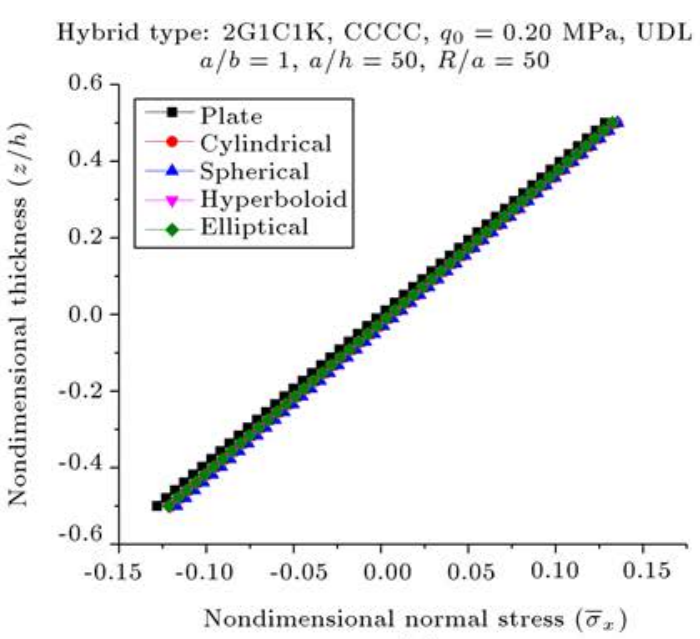

(a)

Hybrid type: $2 \mathrm{G} 1 \mathrm{C} 1 \mathrm{~K}, \mathrm{CCCC}, q_{0}=0.20 \mathrm{MPa}$, UDL $a / b=1, a / h=50, R / a=50$

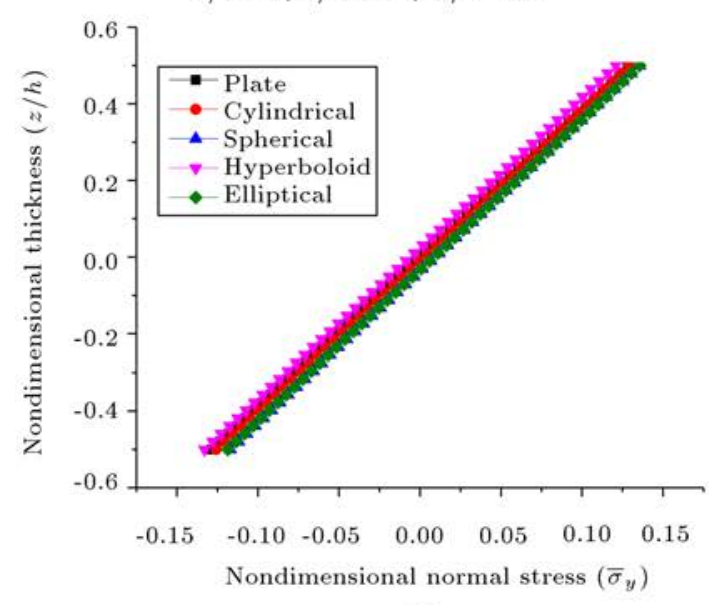

(b)

Hybrid type: $2 \mathrm{G} 1 \mathrm{C} 1 \mathrm{~K}, \mathrm{CCCC}, q_{0}=0.20 \mathrm{MPa}$, UDL $a / b=1, a / h=50, R / a=50$

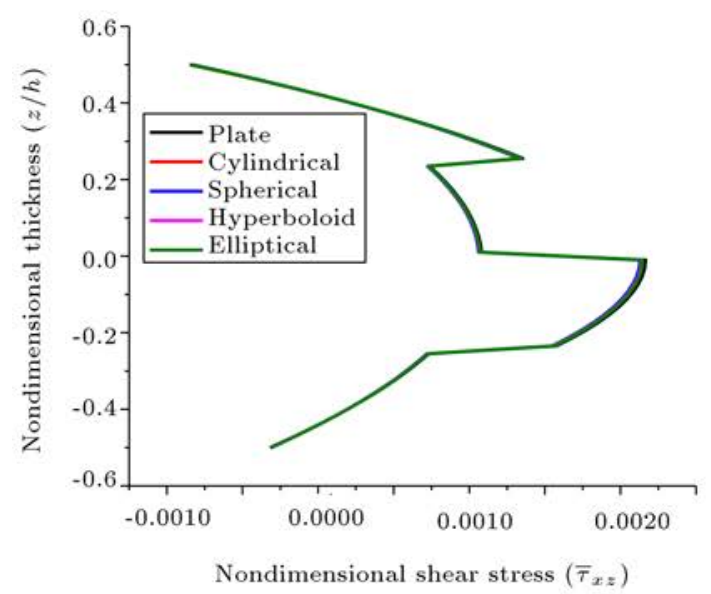

(c)

Figure 10. Variation of in-plane nondimensional stresses through the thickness of 4-layer $2 \mathrm{G} 1 \mathrm{C} 1 \mathrm{~K}$ hybrid clamped square plate under uniform distributed load: (a) Normal stress $\left(\overline{\sigma_{x}}\right),(\mathrm{b})$ normal stress $\left(\overline{\sigma_{y}}\right)$, and $(\mathrm{c})$ shear stress $\left(\overline{\tau_{x z}}\right)$. 
Hybrid type: $4 \mathrm{~K}$, cylindrical, $a / b=1, a / h=50, R / a=50$

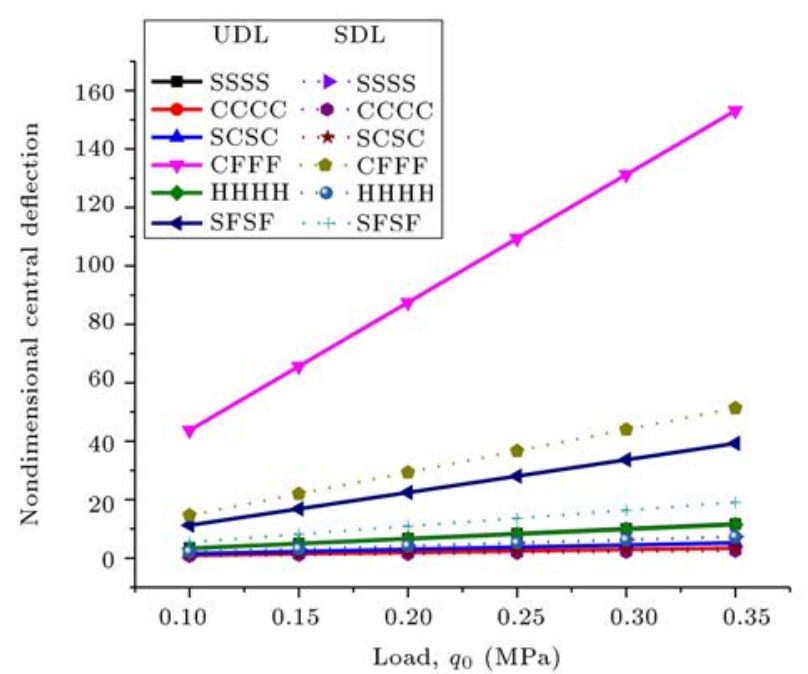

(a)

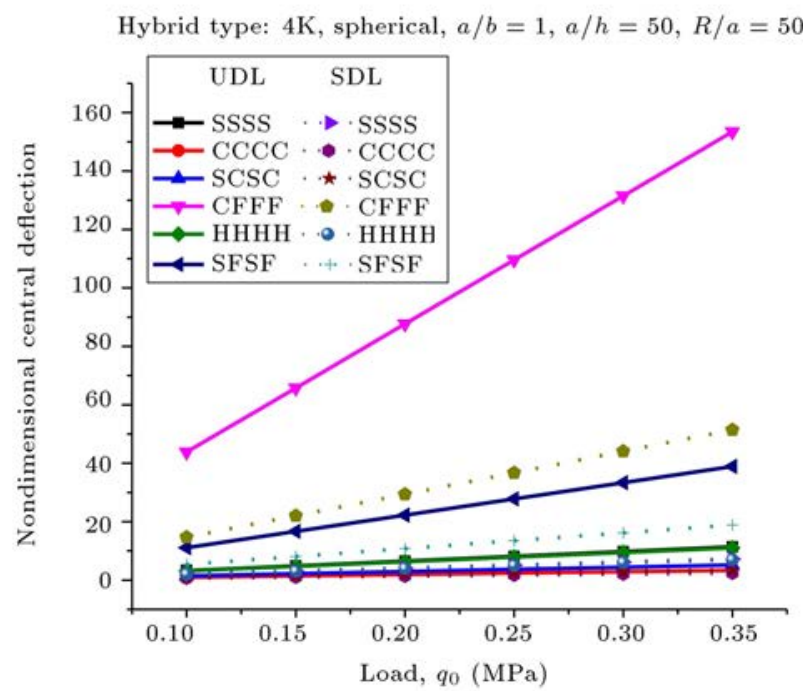

(b)

Figure 11. Nondimensional central deflection for different support conditions under Uniformly Distributed Load (UDL) and Sinusoidally Distributed Load (SDL): (a) Cylindrical and (b) spherical.

\subsubsection{Effect of support condition on the flexural behaviour}

The nondimensional central deflection with varying support condition (SSSS, CCCC, SCSC, CFFF, $\mathrm{HHHH}$, and SFSF $)$ and load intensity $\left(q_{0}=0.10\right.$, $0.15,0.20,0.25,0.30$, and $0.35 \mathrm{MPa}$ ) for a cylindrical and spherical $4 \mathrm{~K}$ hybrid composite panel under both UDL and SDL condition are shown in Figure 11(a) and (b), respectively. The deflection increased as the load increased. The deflection was highest in the case of cantilever type of support (CFFF) followed by SFSF, $\mathrm{HHHH}, \mathrm{SCSC}, \mathrm{CCCC}$, and SSSS cases in the decreasing order. Also, as can be seen in Figure 11, the deflection was higher under the UDL for the corresponding support condition as compared to the SDL.

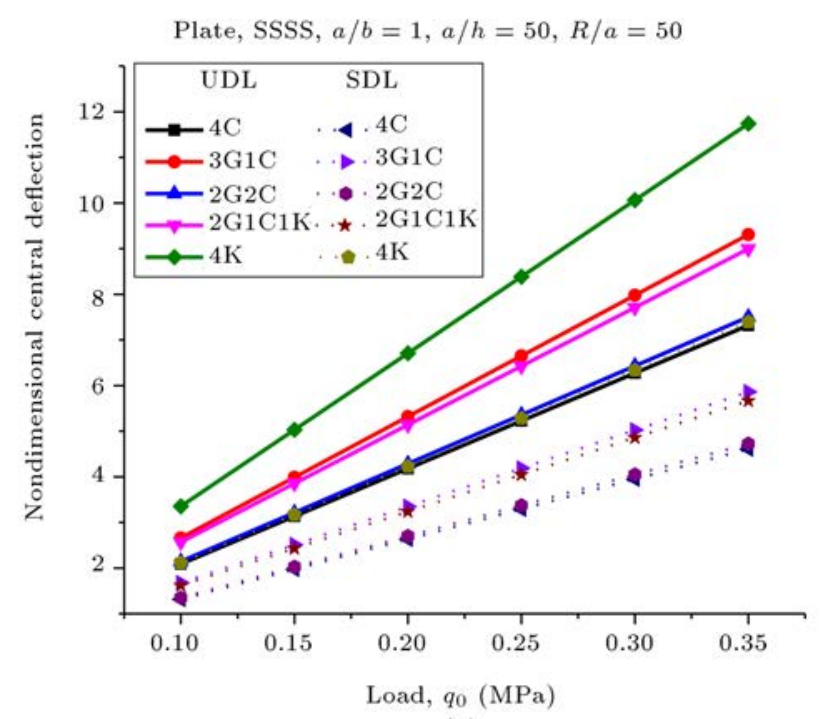

(a)

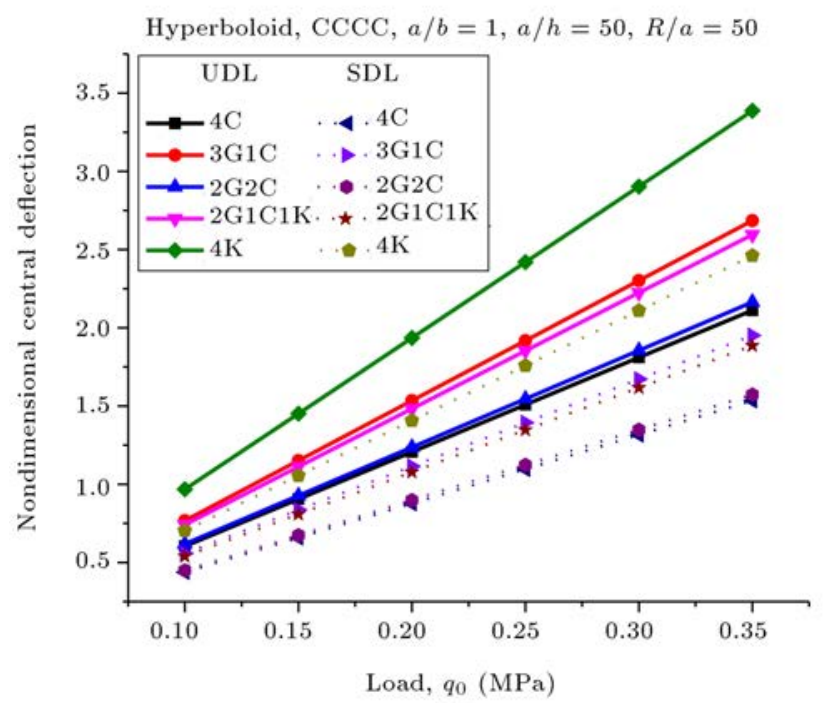

(b)

Figure 12. Nondimensional central deflection for hybrid types under Uniformly Distributed Load (UDL) and Sinusoidally Distributed Load (SDL): (a) Plate, SSSS and (b) hyperboloid, CCCC.

3.2.5. Effect of hybrid types on the flexural behaviour Figure 12(a) shows the nondimensional central deflections with varying hybrid types and load intensity for a square plate under simply support (SSSS) condition and Figure 12(b) shows that for the hyperboloid shell panel under all edges clamped condition (CCCC). The deflections occurred under UDL and SDL. The deflection increased with the increase of load $\left(q_{0}\right)$ for both geometries as is evident in Figure 12(a) and (b). In a descending trend condition, the highest value of deflection was observed in the case of $4 \mathrm{~K}$ hybrid composite panel followed by $3 \mathrm{G} 1 \mathrm{C}, 2 \mathrm{G} 1 \mathrm{C} 1 \mathrm{~K}, 2 \mathrm{G} 2 \mathrm{C}$, and $4 \mathrm{C}$, respectively. Also, it has been observed that the deflections in corresponding hybrid schemes were higher in the case of UDL than under the SDL. 
Interestingly, the variation in normal and shear stresses was insignificant across the hybrid types having cylindrical shell panel geometry with all edges clamped (CCCC) and subjected to UDL of magnitude $q_{0}=$ 0.20 MPa as can be observed in Figure 13(a), (b), and (c), respectively. As seen in the previous example, the displacement decreased with the increase of the percentage of carbon fiber whereas the addition of carbon layers did not affect the bending strength.

\subsubsection{Effect of curvature ratio $(R / a)$ on the flexural behaviour}

Finally, Figure 14(a) and (b) shows the nondimensional central deflections with varying curvature ratio $(R / a=$ $5,10,20,50,100,200)$ for a SSSS and fully clamped (CCCC) spherical shell panel under both the UDL and SDL. The deflections increased with the increase of curvature ratio for all loads. It is due to the fact that the curvature decreased with the increase of curvature ratio leading to a reduction in the stiffness of the panels. Moreover, in agreement with the observations made in the example of the effect of the support conditions, the deflection had a higher value in case of all edge SSSS than all CCCC conditions.

\section{Conclusion}

The originality of the present study lies in the fact that, based on the higher-order kinematic theory, the composite panel stiffness variation following from the hybridization of different kinds of advanced fiber was examined for the first time. In this regard, the structural strength was verified by evaluating the flexural deflection and stress values due to the inclusion of different advanced fibers (carbon/glass/kevlar). The responses are predicted using the higher-order Finite Element Method (FEM) by solving the structural equilibrium equation obtained through the variational principle. To obtain the responses, a computer code was developed using MATLAB software.

- Firstly, the convergence of the model is ensured and the validity of the responses is established by the comparison study;

- The deflections are showed an increasing trend when the thickness ratio and the aspect ratio values increased;

- This was because the structure became thin and slender with the increase in thickness ratio and the aspect ratio, respectively;

- The responses showed a reverse trend, i.e. a decreasing trend was observed when the panel curvature increased and the shallowness increased, which, in turn, caused the stretching energy to be reduced in comparison to the bending strength;

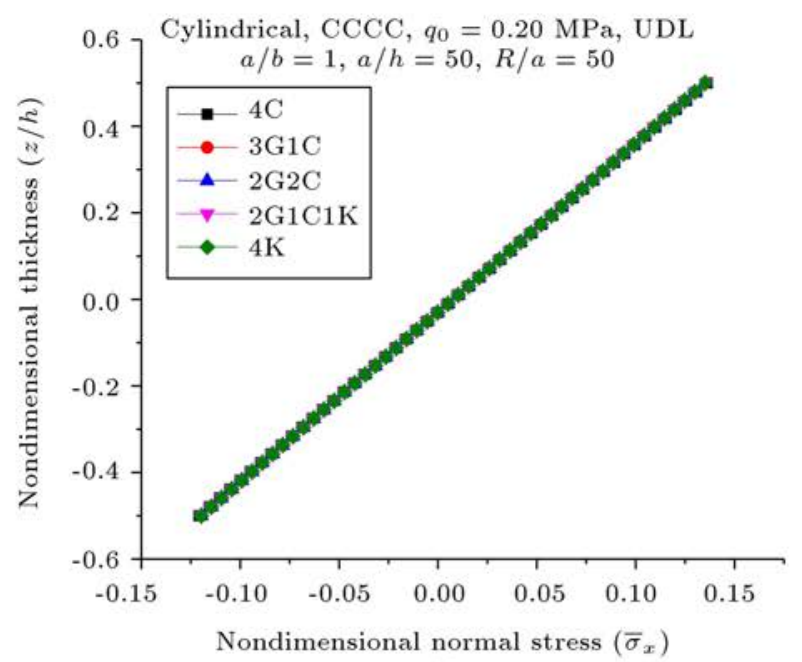

(a)

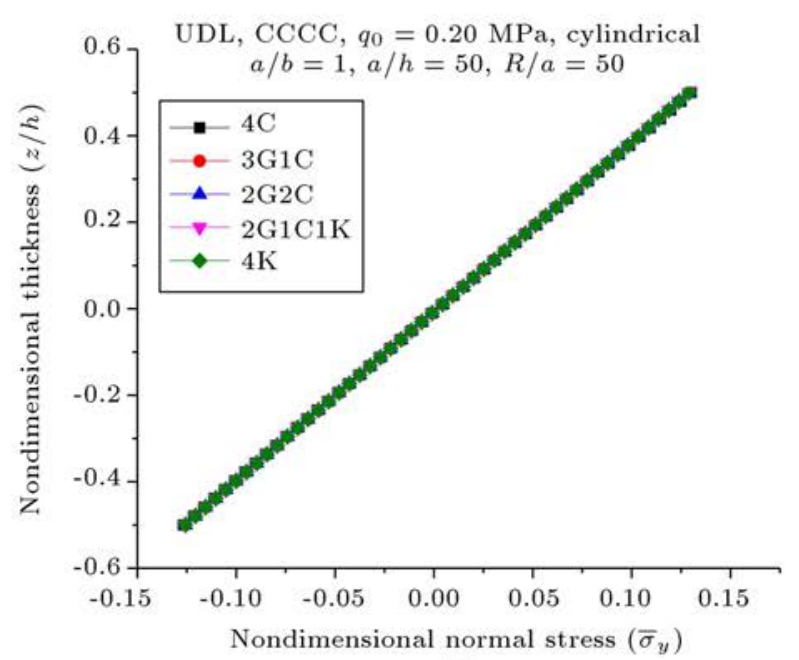

(b)

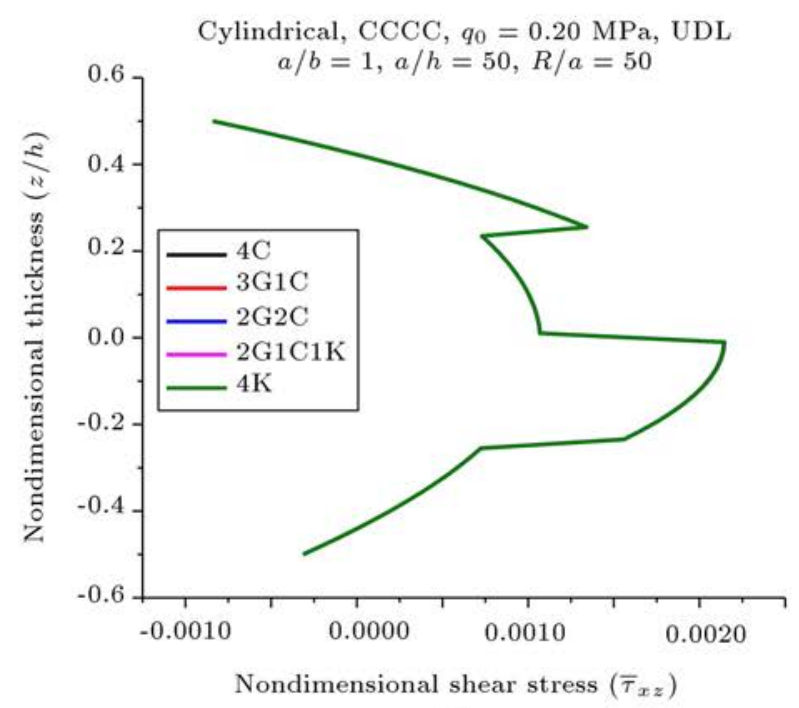

(c)

Figure 13. Variation of in-plane nondimensional stresses through the thickness of clamped cylindrical shell panel of different hybrid schemes under uniform distributed load: (a) $\left(\overline{\sigma_{x}}\right)$, (b) $\left(\overline{\sigma_{y}}\right)$, and $(\mathrm{c})\left(\overline{\tau_{x z}}\right)$. 


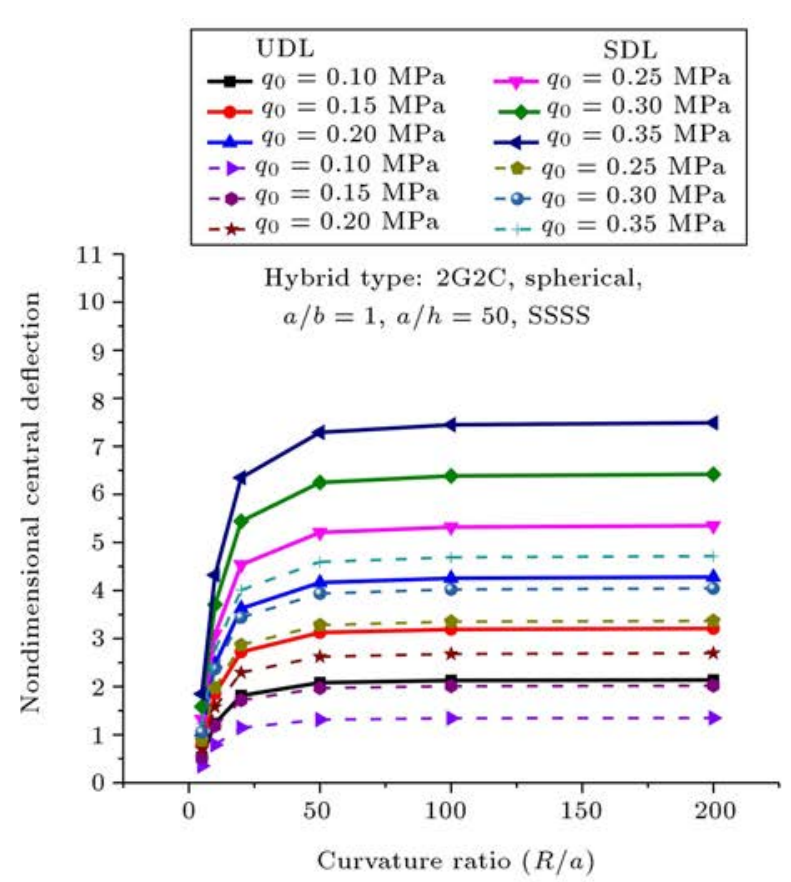

(a)

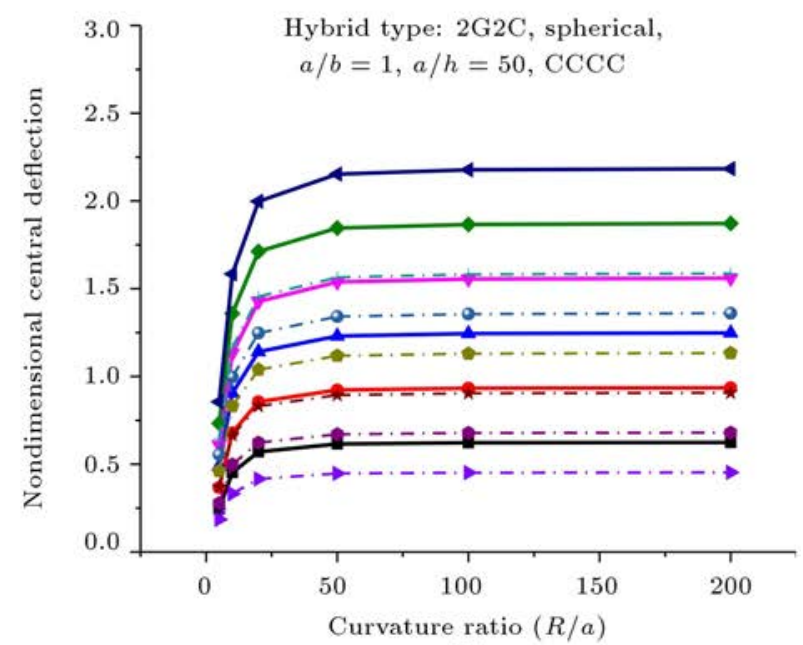

(b)

Figure 14. Nondimensional central deflection of the spherical panel for different curvature ratio $(R / a)$ under Uniformly Distributed Load (UDL) and Sinusoidally Distributed Load (SDL) with two different support conditions: (a) SSSS and (b) CCCC.

- The maximum and minimum value of the deflection data was observed for the simply-supported and clamped type which resulted from the enhancement of the total structural stiffness;

- The types of loading had a significant role in the structural deflections due to the total area of application, i.e. higher under Uniformly Distributed Load (UDL) whereas lower under Sinusoidally Distributed Load (SDL);

- The change of panel geometries had an insignificant effect on the deflection parameter; The deflection

due to the hybridization was maximum i.e. flexural structure for $4 \mathrm{~K}$ type of composite panels and followed by $3 \mathrm{G} 1 \mathrm{C}, 2 \mathrm{G} 1 \mathrm{C} 1 \mathrm{~K}, 2 \mathrm{G} 2 \mathrm{C}$, and $4 \mathrm{C}$, respectively;

- The nondimensional form of the normal $\left(\overline{\sigma_{x}}, \overline{\sigma_{y}}\right)$ and shear stress $\left(\overline{\tau_{x z}}\right)$ values followed the same trend as that of the deflection while the thickness and the aspect ratios increased;

- The nondimensional normal and shear stress values were invariant for all types of hybridization while they were constant for every kind of geometry at a specific loading intensity;

- The normal and shear stress values were higher for the hinged and cantilever types of end support, respectively.

\section{Nomenclature}

$a, b, h$

$(a / b)$

$(a / h)$

$\partial$

$\{\delta\}$

$\{\bar{\delta}\}$

$\left\{\delta_{i}\right\}$

$\{\varepsilon\}$

$\{\bar{\varepsilon}\}$

$\{\sigma\}$

$\sigma_{x}, \sigma_{y}$

$\tau_{x z}$

[D]

$\left[D_{L}\right]$

$E_{1}, E_{2}, E_{3}$

$G_{12}$

$G_{13}, G_{23}$

$[K]$

$[F]$

$N$

$N_{i}$

II

$p, q$

$q_{0}$

$[\bar{Q}]$

$R_{x}, R_{y}$
Length, width, and thickness of the shell panel

Aspect ratio

Thickness ratio

The variational symbol

Global displacement field vector

The global displacement vector

Displacement vector for $i$ th node

Strain vectors

Mid-plane strain vectors

The stress vector

In-plane normal stresses along $x$ and $y$-directions

Transverse shear stress

The elements of the stiffness matrix

Matrix of partial derivatives of shape function

Young modulus in the principal material direction

In-plane shear modulus

Out-of-plane shear moduli

The global system stiffness matrix

The load vectors

Shape function (interpolation function)

Nodal interpolating functions at $i$ th node

The total energy functional

Load function

Load factor

Reduced stiffness matrix

Radius of curvature in longitudinal and transverse directions, respectively 


$\begin{array}{ll}R / a & \begin{array}{l}\text { Curvature ratio } \\ u_{l}, v_{m}, w_{n}\end{array} \\ & \begin{array}{l}\text { Displacements of any point along } \\ \text { the } x, y, \text { and } z \text { principal material } \\ \text { coordinate axes, respectively }\end{array} \\ u_{l 0}, v_{m 0}, w_{n 0} & \begin{array}{l}\text { Corresponding displacements of a } \\ \text { point on the mid-plane }\end{array} \\ u_{l 1}, v_{m 1} & \begin{array}{l}\text { Rotations of normal about } y \text { and } \\ \text { x-axes, respectively, at the mid-surface }\end{array} \\ u_{l 2}, v_{m 2}, & \text { Higher-order terms assumed from } \\ u_{l 3}, v_{m 3} & \text { Taylor series expansion } \\ U & \text { The strain energy } \\ W & \text { The total work done } \\ w_{c} & \text { Central deflection } \\ \bar{w} & \text { Nondimensional central deflection } \\ {\left[Z_{d}\right],\left[Z_{e}\right]} & \text { The thickness coordinate matrices } \\ \nu & \text { Poisson ratio } \\ \rho & \text { Density of material, kg/m }{ }^{3} \\ x, y, z & \text { Principal material coordinate axes }\end{array}$

\section{References}

1. Wang, Y., Li, J., and Zhao, D. "Mechanical properties of fiber glass and kevlar woven fabric reinforced composites", Compos. Eng., 5(9), pp. 1159-1175 (1995). DOI: $10.1016 / 0961-9526(95) 00100-2$

2. Matykiewicz, D. "Hybrid epoxy composites with both powder and fiber filler: A review of mechanical and thermomechanical properties", Materials, 13, pp. 122 (2020). DOI: 10.3390/MA13081802

3. Valenca, S.L., Griza, S., de Oliveira, V.G., Sussuchi, E.M., and de Cunha, F.G.C. "Evaluation of the mechanical behaviour of epoxy composites reinforced with kevlar plain fabric and glass/kevlar hybrid fabric", Compos. Part B, 70, pp. 1-8 (2015).

DOI: $10.1016 /$ j.compositesb.2014.09.040

4. Jarukumjorn, K., and Suppakarn, N. "Effect of glass fiber hybridization on properties of sisal fiberpolypropylene composites", Compos. Part B, 40, pp. 623-627 (2009).

DOI: $10.1016 /$ j.compositesb.2009.04.007

5. Reis, P.N.B., Ferreira, J.A.M., Antunes, F.V., and Costa, J.D.M. "Flexural behaviour of hybrid laminated composites", Compos. Part A Appl. Sci. Manuf., 38, pp. $1612-1620$ (2007).

DOI: $10.1016 /$ j.compositesa.2006.11.010

6. Dorigato, A. and Pegoretti, A. "Flexural and impact behaviour of carbon/basalt fibers hybrid laminates", J. Compos. Mater, 48, pp. 1121-30 (2014). DOI: $10.1177 / 0021998313482158$

7. Ary Subagia, I.D.G., and Kim, Y. "A study on flexural properties of carbon-basalt/epoxy hybrid composites", J. Mech. Sci. Technol., 27(4), pp. 987-992 (2013). DOI: $10.1007 / \mathrm{s} 12206-013-0209-5$
8. Pandya, K.S., Veerraju, C., and Naik, N.K. "Hybrid composites made of carbon and glass woven fabrics under quasi-static loading", Mater. Des., 32(7), pp. 4094-4099 (2011). DOI: 10.1016/j.matdes.2011.03.003

9. Subagia, I.D.G.A., Kim, Y., Tijing, L.D., Kim, C.S., and Shon, H.K. "Effect of stacking sequence on the flexural properties of hybrid composites reinforced with carbon and basalt fibers", Compos: Part B, 58, pp. 251-258 (2014). DOI: 10.1016/j.compositesb.2013.10.027

10. Wang, Q., Wu, W., Gong, Z., and Li, W. "Flexural progressive failure of carbon/glass interlayer and intralayer hybrid composites", Materials, 11(4), pp. 118 (2018). DOI: 10.3390/ma11040619

11. Fischer, S. and Marom, G. "The flexural behaviour of aramid fibre hybrid composite materials", Compos. Sci. Technol., 28(4), pp. 291-314 (1987). DOI: 10.1016/0266-3538(87)90027-3

12. Dong, C., Ranaweera-Jayawardena, H.A., and Davies, I.J. "Flexural properties of hybrid composites reinforced by S-2 glass and T700S carbon fibres", Compos. Part B, 43(2), pp. 573-581 (2012). DOI: $10.1016 /$ j.compositesb.2011.09.001

13. Dong, C. and Davies, I.J. "Flexural properties of Eglass and TR50S carbon fiber reinforced epoxy hybrid composites", J. Mater. Eng. Perform, 22, pp. 41-49 (2013). DOI: $10.1007 / \mathrm{s} 11665-012-0247-7$

14. Dong, C. and Davies, I.J. "Flexural properties of glass and carbon fiber reinforced epoxy hybrid composites", J. Mater. Des. Appl., 227(4), pp. 308-317 (2012). DOI: $10.1177 / 1464420712459396$

15. Dong, C., Duong, J., and Davies, I.J. "Flexural properties of S-2 Glass and TR30S carbon fiber-reinforced epoxy hybrid composites", Polym. Compos., 37(1), pp. 915-924 (2012). DOI: 10.1002/pc.22206

16. Naidu, P.P., Raghavendra, G., Ojha, S., and Paplal, B. "Effect of $\mathrm{g}-\mathrm{C}_{3} \mathrm{~N}_{4}$ nanofiller as filler on mechanical properties of multidirectional glass fiber epoxy hybrid composites", J. Appl. Polym. Sci., 137, pp. 1-9 (2020). DOI: $10.1002 /$ app.48413

17. Doddi, P.R.V., Chanamala, R., and Dora, S.P. "Effect of fiber orientation on dynamic mechanical properties of PALF hybridized with basalt reinforced epoxy composites", Mater. Res. Express, 7, p. 015329 (2020). DOI: $10.1088 / 2053-1591 / a b 6771$

18. James, D.J.D., Manoharan, S., Saikrishnan, G., and Arjun, S. "Influence of Bagasse/Sisal fibre stacking sequence on the mechanical characteristics of hybridepoxy composites", J. Nat. Fibers, 17, pp. 1497-1507 (2019). DOI: 10.1080/15440478.2019.1581119

19. Arani, A.G., Mosayyebi, M., Kolahdouzan, F., Kolahchi, R., and Jamali, M. "Refined zigzag theory for vibration analysis of viscoelastic functionally graded carbon nanotube reinforced composite microplates integrated with piezoelectric layers", $J$. Aerosp. Eng., 231, pp. 2464-2478 (2017). DOI: $10.1177 / 0954410016667150$ 
20. Szekrenyes, A. "Application of Reddy's third-order theory to delaminated orthotropic composite plates", Eur. J. Mech. / A Solids, 43, pp. 9-24 (2014). DOI: 10.1016/j.euromechsol.2013.08.004

21. Belbachir, N., Bourada, M., Draiche, K. et al. "Thermal flexural analysis of anti-symmetric cross-ply laminated plates using a four variable refined theory", Smart Struct. Syst., 25(4), pp. 409-422 (2020). DOI: 10.12989/SSS.2020.25.4.409

22. Draiche, K., Bousahla, A.A., Tounsi, A. et al. "Static analysis of laminated reinforced composite plates using a simple first-order shear deformation theory", Comput. Concr., 24(4), pp. 369-378 (2019). DOI: 10.12989/CAC.2019.24.4.369

23. Abualnour, M., Chikh, A., Hebali, H. et al. "Thermomechanical analysis of antisymmetric laminated reinforced composite plates using a new four variable trigonometric refined plate theory", Comput. Concr., 24(6), pp. 489-98 (2019). DOI: 10.12989/CAC.2019.24.6.489

24. Allam, O., Draiche, K., Bousahla, A.A. et al. "A generalized 4-unknown refined theory for bending and free vibration analysis of laminated composite and sandwich plates and shells", Comput. Concr., 26(2), pp. 185-201 (2020). DOI: 10.12989/CAC.2020.26.2.185

25. Belbachir, N., Draich, K., Bousahla, A.A., Bourada, M., Tounsi, T., and Mohammadimehr, M. "Bending analysis of anti-symmetric cross-ply laminated plates under nonlinear thermal and mechanical loadings", Steel Compos. Struct., 33(1), pp. 81-92 (2019). DOI: 10.12989/SCS.2019.33.1.081

26. Sahla, M., Saidi, H., Draiche, K., Bousahla, A.A., Bourada, F., and Tounsi, A. "Free vibration analysis of angle-ply laminated composite and soft core sandwich plates", Steel Compos. Struct., 33(5), pp. 663-679 (2019). DOI: $10.12989 /$ scs.2019.33.5.663

27. Rahmani, M.C., Kaci, A., Bousahla, A.A. et al. "Influence of boundary conditions on the bending and free vibration behavior of FGM sandwich plates using a four-unknown refined integral plate theory", Comput. Concr., 25(3), pp. 225-244 (2020). DOI: 10.12989/CAC.2020.25.3.225

28. Refrafi, S., Bousahla, A.A., Bouhadra, A., Menasria, A., Bourada, F., Tounsi, A., Adda Bedia, E.A., Mahmoud, S.R., Benrahou, K.H., and Tounsi, A. "Effects of hygro-thermo-mechanical conditions on the buckling of FG sandwich plates resting on elastic foundations", Comput. Concr., 25(4), pp. 311-325 (2020). DOI: 10.12989/CAC.2020.25.4.311

29. Menasria, A., Kaci, A., Bousahla, A.A., Bourada, F., Tounsi, A., Benrahou, H.K., Tounsi, A., Adda Bedia, E.A., and Mahmoud, S.R. "A four-unknown refined plate theory for dynamic analysis of FGsandwich plates under various boundary conditions", Steel Compos. Struct., 36(3), pp. 355-367 (2020). DOI: $10.12989 /$ scs.2020.36.3.355

30. Zine, A., Bousahla, A.A., Bourada, F., Benrahou, K.H., Tounsi, A., Adda Bedia, E.A., Mahmoud, S.R., and Tounsi, A. "Bending analysis of functionally graded porous plates via a refined shear deformation theory", Comput. Concr., 26(1), pp. 63-74 (2020). DOI: $10.12989 / \mathrm{CAC} .2020 .26 .1 .063$

31. Alimirzaei, S., Mohammadimehr, M., and Tounsi, A. "Nonlinear analysis of viscoelastic micro-composite beam with geometrical imperfection using FEM: MSGT electro-magneto-elastic bending, buckling and vibration solutions", Struct. Eng. Mech., 71(5), pp. 485-502 (2019). DOI: 10.12989/SEM.2019.71.5.485

32. Al-Furjan, M.S.H., Habibi, M., Jung, D. won, Sadeghi, S., Safarpour, H., Tounsi, A., and Chen, G. "A computational framework for propagated waves in a sandwich doubly curved nanocomposite panel", Eng. Comput. (2020). DOI: 10.1007/s00366-020-01130-8

33. Reddy, J.N. and Liu, C.F. "A higher-order shear deformation theory of laminated elastic shells", J. Eng. Sci., 23(3), pp. 319-330 (1985). DOI: 10.1016/0020$7225(85) 90051-5$

34. Xiao, J.R., Gilhooley, D.F., Batra, R.C., Gillespie, J.W., and McCarthy, M.A. "Analysis of thick composite laminates using a higher-order shear and normal deformable plate theory (HOSNDPT) and a meshless method", Compos. Part B Eng., 39(2), pp. 414-427 (2008). DOI: 10.1016/j.compositesb.2006.12.009

35. Achryya, A.K., Chakravorty, D., and Karmakar, A. "Bending characteristics of delaminated composite cylindrical shells-A finite element approach", J. Reinf. Plast Compos., 28(8), pp. 965-978 (2009). DOI: 10.1177/0731684407087585

36. Hirwani, C.K., Panda, S.K., Mahapatra, S.S., Mandal, S.K., Srivastava, L., and Buragohain, M.K. "Flexural strength of delaminated composite plate: An experimental validation", Int. J. Damage Mech., 27(2), pp. 296-329 (2018). DOI: 10.1177/1056789516676515

37. Cunedioglu, Y. and Beylergil, B. "Free vibration analysis of laminated composite beam under room and high temperatures", Struct. Eng. Mech., 51(1), pp. 111-130 (2014). DOI: 10.12989/sem.2014.51.1.111

38. Cunedioglu, Y. and Beylergil, B. "Free vibration analysis of damaged composite beams", Struct. Eng. Mech., 55(1), pp. 79-92 (2015).

DOI: $10.12989 /$ sem.2015.55.1.079

39. Beylergil, B. "Multi-objective optimal design of hybrid composite laminates under eccentric loading", Alexandria Eng. J., 59(6), pp. 4969-4983 (2020). DOI: 10.1016/j.aej.2020.09.015

40. Dong, C. and Davies, I.J. "Effect of stacking sequence on the flexural properties of carbon and glass fibrereinforced hybrid composites", Adv. Compos. Hybrid Mater., 1, pp. 530-540 (2018). DOI: $10.1007 / \mathrm{s} 42114-$ 018-0034-5

41. Dong, C. and Davies, I.J. "Optimal design for the flexural behaviour of glass and carbon fibre reinforced polymer hybrid composites", Mater. Des., 37, pp. 450457 (2012). 
42. Alipour, M.M. "An analytical approach for bending and stress analysis of cross/angle-ply laminated composite plates under arbitrary non-uniform loads and elastic foundations", Arch. Civ. Mech. Eng., 16(2), pp. 193-210 (2016). DOI: 10.1016/j.acme.2015.11.001

43. Mehar, K. and Panda, S.K. "Elastic bending and stress analysis of carbon nanotube-reinforced composite plate: Experimental, numerical, and simulation", Adv Polym Technol, 37(6), pp. 1643-1657 (2018). DOI: 10.1002/adv. 21821

44. Bendenia, N., Zidour, M., Bousahla, A.A., Bourada, F., Tounsi, A., Benrahou, K.H., Adda Bedia, E.A., Mahmoud, S.R., and Tounsi, A. "Deflections, stresses and free vibration studies of FG-CNT reinforced sandwich plates resting on Pasternak elastic foundation", Comput. Concr., 26(3), pp. 213-26 (2020). DOI: 10.12989/CAC.2020.26.3.213

45. Bousahla, A.A., Bourada, F., Mahmoud, S.R., Tounsi, A., Algarni, A., Adda Bedia, E.A., and Tounsi, A. "Buckling and dynamic behavior of the simply supported CNT-RC beams using an integral-first shear deformation theory", Comput. Concr., 25(2), pp. 155166 (2020). DOI: 10.12989/CAC.2020.25.2.155

46. Medani, M., Benahmed, A., Zidour, M., Heireche, H., Tounsi, A., Bousahla, A.A., Tounsi, A., and Mahmoud, S.R. "Static and dynamic behavior of (FGCNT) reinforced porous sandwich plate using energy principle", Steel Compos. Struct., 32(5), pp. 595-610 (2019). DOI: $10.12989 /$ scs.2019.32.5.595

47. Bourada, F., Bousahla, A.A., Tounsi, A., Adda Bedia, E.A., Mahmoud, S.R., Benrahou, K.H., and Tounsi, A. "Stability and dynamic analyses of SW-CNT reinforced concrete beam resting on elastic-foundation", Comput. Concr., 25(6), pp. 485-495 (2020). DOI: 10.12989/CAC.2020.25.6.485

48. Zhu, P., Lei, Z.X., and Liew, K.M. "Static and free vibration analyses of carbon nanotube-reinforced composite plates using finite element method with first order shear deformation plate theory", Compos. Struct., 94(4), pp. 1450-1460 (2012). DOI: 10.1016/j.compstruct.2011.11.010

49. Lei, Z.X., Yin, B.B., and Liew, K.M. "Bending and vibration behaviors of matrix cracked hybrid laminated plates containing CNTR-FG layers and FRC layers", Compos. Struct., 184, pp. 314-326 (2018). DOI: $10.1016 /$ j.compstruct.2017.10.004
50. Sahu, P., Sharma, N., and Panda, S.K. "Numerical prediction and experimental validation of free vibration responses of hybrid composite (Glass/ Carbon/Kevlar) curved panel structure", Compos. Struct., 241, p. 112073 (2020).

DOI: $10.1016 /$ j.compstruct.2020.112073

51. Cook, R.D., Malkus, D.S., and Plesha, M.E., Concepts and Applications of Finite Element Analysis, 3rd Ed., Singapore: John Willy and Sons (2000).

52. Kant, T. and Swaminathan, K. "Analytical solutions for the static analysis of laminated composite and sandwich plates based on a higher order refined theory", Compos. Struct., 56(4), pp. 329-344 (2002). DOI: $10.1016 / \mathrm{S} 0263-8223(02) 00017-\mathrm{X}$

\section{Biographies}

Pruthwiraj Sahu, the lead author, is working as an Assistant Professor (I) and pursuing $\mathrm{PhD}$ in the School of Mechanical Engineering, KIIT (deemed to be university) Bhubaneswar, India. He has completed his Masters of Technology in the area of Mechanical Systems Design in 2013 from IIT Kharagpur, India. His research field is the modelling of composite structures using the finite element technique.

Nitin Sharma is working as an Associate Professor (I) in the School of Mechanical Engineering, KIIT (deemed to be university) Bhubaneswar, India. His area of interest includes computational mechanics, finite-/boundary-element methods, vibroacoustics, and mechanics of composite structures.

Subrata Kumar Panda is working as an Associate Professor in the Department of Mechanical Engineering, NIT, Rourkela, India. He received his $\mathrm{PhD}$ from IIT Kharagpur, India, in 2009 and his research interests include nonlinear solid mechanics, smart composite structures, nonlinear FEM, experimental vibrations, functionally graded materials, SMA, PZT, and magnetostrictive material, biomechanical analysis of functional materials, hybrid composite structures. 